\title{
High thermal conductive copper/diamond composites: state of the art
}

\author{
S. Q. Jia ${ }^{1}$ and F. Yang ${ }^{1, *}$ \\ ${ }^{1}$ Waikato Centre for Advanced Materials and Manufacturing, School of Engineering, University of Waikato, Hamilton 3240, New \\ Zealand
}

Received: 22 July 2020

Accepted: 24 September 2020

Published online:

20 October 2020

(C) The Author(s) 2020

\begin{abstract}
Copper/diamond composites have drawn lots of attention in the last few decades, due to its potential high thermal conductivity and promising applications in high-power electronic devices. However, the bottlenecks for their practical application are high manufacturing/machining cost and uncontrollable thermal performance affected by the interface characteristics, and the interface thermal conductance mechanisms are still unclear. In this paper, we reviewed the recent research works carried out on this topic, and this primarily includes (1) evaluating the commonly acknowledged principles for acquiring high thermal conductivity of copper/diamond composites that are produced by different processing methods; (2) addressing the factors that influence the thermal conductivity of copper/diamond composites; and (3) elaborating the interface thermal conductance problem to increase the understanding of thermal transferring mechanisms in the boundary area and provide necessary guidance for future designing the composite interface structure. The links between the composite's interface thermal conductance and thermal conductivity, which are built quantitatively via the developed models, were also reviewed in the last part.
\end{abstract}

\section{Introduction}

Miniaturization of electronic devices makes it challenge to dissipate heat generated during operation. The insufficient thermal conductivity and heat dissipation rate of heat sinks would increase the electronic devices' working temperature, and this dramatically degrades its working performance and efficiency.
Besides, the electronic packaging becomes multiplelayer structures, and this causes more thermally challenging [1]. Until now, the most efficient cooling method for electronic system is still by fans and circulated cooling water, which consumes large amounts of additional electric energy [2]. According to one statistic from the US data center, one-third of the total power consumption is expected to be used in

Handling Editor: Catalin Croitoru.

Address correspondence to E-mail: fei.yang@waikato.ac.nz 
cooling the electronic system by 2025 [3]. The heat management problem is the bottleneck for sustaining and improving the performance of the high-power density electronic devices used everywhere today. The utilization of suitable materials with high thermal conductivity is essential for efficient heat dissipation from hot spots and improving the electronic device's performance. To understand the mechanisms of interface thermal conductance can not only improve the thermal conductivity of the composites, but help assembly the heat management structure efficiently.

Copper/diamond composites have the potential to be used as the next-generation heat sink materials in advanced electronic devices, and this is because (1) the artificial diamond as a metal matrix composites reinforcement has the highest thermal conductivity (TC) up to $2200 \mathrm{~W} /(\mathrm{m} \mathrm{K})$ in nature $[1,4]$; (2) the coefficient of thermal expansion (CTE) of copper/diamond composites could be tailored to be close to that of semiconductor chip materials (4-6 ppm/K) [5]; (3) the TC of copper/diamond composites could reach 500-900 W/(m K) [6-11]; and (4) the copper/diamond composite is stable at ambient temperature and has isotropic thermal conductivity, which doesn't limit its wide applications [12]. However, the chemical affinity between the copper and the diamond particles is poor, which makes copper and diamond hardly bond together. The interface between the copper and the diamond particles is very important in the copper/diamond composites, and it has a bridging effect to help transfer the heat between the reinforcement and the matrix. Hence, the interface characteristics can influence the composites' properties significantly [13, 14].

Carbide-forming metal elements such as $\mathrm{Cr}, \mathrm{B}, \mathrm{Mo}$, $\mathrm{Ti}$, and $\mathrm{Zr}$ can be added in the copper matrix in the copper/diamond composites to form a chemical bonding (metal carbides layer) between the copper matrix and the diamond particles, which helps bridge the diamond and copper matrix and improve the thermal boundary conductance [15]. A similar effect could be achieved by using the carbide-forming elements-coated diamond particles to fabricate copper/diamond composites. Most of the earlier literature's themes on copper/diamond composites are toward the fabrication process of copper/diamond composites with high thermal conductivity value by designing different processing parameters based on materials thermal dynamics principle and collate the TC prediction value by different models to the experimental results [16-21]. Some research works characterized the morphology of the interface area and identified phases formed at the interface layer [9, 22-24]. Some of them modified the interface thermal conductance parts in TC models based on the interface characteristics to make the TC prediction value close to the experimental value $[19,25,26]$. For copper/diamond composites, it still lacks a deep understanding on how the interface characteristics affect heat transfer behavior. The research on the thermal conductance problems that have been carried out in other materials systems such as between specific metal elements and dielectric materials (including some dielectric materials like sapphire, diamond) can give us some insights to deal with the similar problems in the copper/diamond composites interface and provide guidance on the interface design [27-29]. We will delve into the related research and try to connect it with the interface thermal conductance problems in the copper/diamond composite.

In this review, we begin with generalizing and comparing the commonly used fabrication methods of copper/diamond composites, to evaluate their primary experimental results and findings, and then address the factors that could affect the copper/diamond composite's thermal conductivity. The interface-related problems, which determine the thermal conductivity of copper/diamond composites, are particularly emphasized and discussed in the perspective of classic lattice dynamic theory. Finally, the models for predicting the thermal conductivity of copper/diamond composites combined with the interface thermal conductance are reviewed.

\section{Fabrication and thermal conductivity of copper/diamond composites}

\section{Vacuum hot pressing method}

Vacuum hot pressing (VHP) is a method that could hold pressure and temperature at the same time for powder consolidation (as shown in Fig. 1) [30], which is generally used for fabricating highly densified powder metallurgy materials. VHP usually holds the desired temperature and pressure for longer time compared to the spark plasma sintering (SPS) method (to be mentioned later). This trait promotes the 


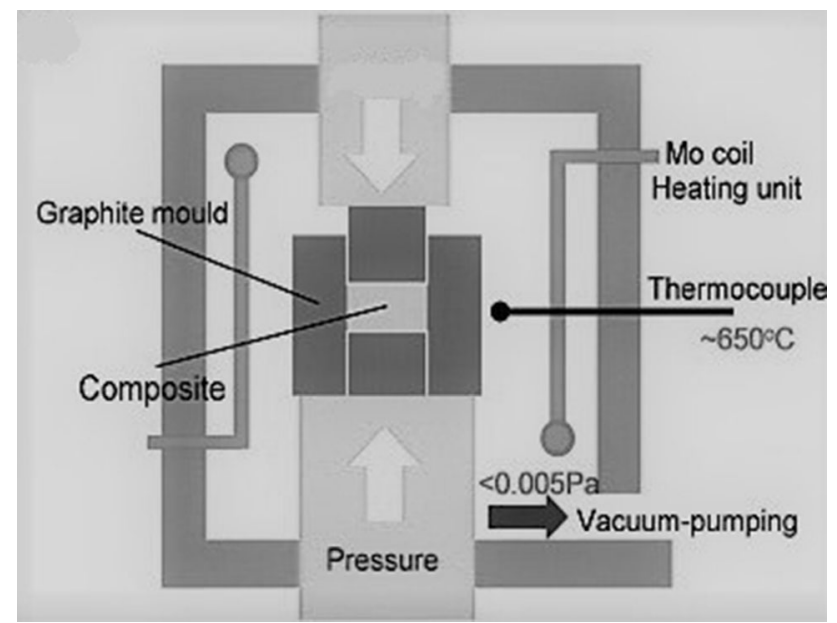

Figure 1 Vacuum hot pressing diagram [30].

element diffusivity between powder particles, thus enhancing the interface bonding strength between the copper matrix and the diamond particles.

Some experimental results of the copper/diamond composites fabricated by VHP methods with different processing parameters are listed in Table 1. The thermal conductivity value of the fabricated copper/diamond composites varies with the contents of carbide-forming additives $(\mathrm{B}, \mathrm{Zr}$, and $\mathrm{Cr}$ ) that are added via using coated diamond particles or copper alloying [18-20, 31, 32].

Chu finds that the TC values increase first and then decrease with the $\mathrm{Zr}$ content increasing from 0 to $2.4 \mathrm{wt} \%$, and the thickness of carbide interface layers is $0 \mathrm{~nm}, 270 \mathrm{~nm}, 320 \mathrm{~nm}, 480 \mathrm{~nm}$, respectively, for the composites with $\mathrm{Zr}$ contents of $0,0.8 \mathrm{wt} \%$, $1.2 \mathrm{wt} \%$, and $2.4 \mathrm{wt} \%$, as shown in Fig. 2 [32]. It suggests that there exists an optimal content of carbide-forming additives to obtain a desired thickness of interface layers and high thermal conductivity for the copper/diamond composites. The interface layer with optimal thickness leads to high interface thermal conductance and improves the efficiency of heat transfer from the diamond particles to the copper matrix [34]. The low content of metal additives in the copper/diamond composites is not enough to form interface layers that completely cover all diamond particle surfaces, leading to reducing the interface thermal conductance. However, adding a large number of metal additives in the composite is prone to form an interface layer with large thickness, which is detrimental for improving interface thermal conductance. These align well with the experimental results shown in Fig. 2.

Interface thermal conductance "hc" (as shown in Table 1) represents the thermal transfer efficiency from the diamond particles to the copper matrix. The higher the value is, the better the interface layer functions as a thermal transfer "bridge," so that higher thermal conductivity of composites could be obtained.

The "hc" values listed in Table 1 (including the " $h c^{\text {" }}$ in the table below) are obtained by prediction, not by experimental measurement. The principles of the prediction process are briefly illustrated in Fig. 3. When calculating "hc" with the model shown in the picture, " $R$ " is defined as thermal resistance, and the relationship between " $R$ " and "hc" is:

$R=\frac{1}{h c}$

For the case in Fig. $3, R=R_{\mathrm{Cu} / \mathrm{B} 4 \mathrm{C}}+R_{\mathrm{B} 4 \mathrm{C}-}$ $+R_{\mathrm{B} 4 \mathrm{C} / \text { diamond }} . R_{\mathrm{B} 4 \mathrm{C}}$ can be obtained by the equation: $R_{\mathrm{B} 4 \mathrm{C}}=\frac{d}{\lambda}$, where " $d$ " is the thickness of the $\mathrm{B}_{4} \mathrm{C}$ layer

Table 1 Thermal conductivity and calculated interface thermal conductance of copper/diamond composites fabricated by VHP

\begin{tabular}{|c|c|c|c|c|c|c|c|}
\hline Authors & Processing parameters & Raw materials & $\begin{array}{l}\text { Dia. } \\
(\mu \mathrm{m})\end{array}$ & $\begin{array}{l}V_{\mathrm{f}} \\
(\%)\end{array}$ & $\begin{array}{l}\text { The thickness of } \\
\text { the interface } \\
\text { layer }(\mathrm{nm})\end{array}$ & $\begin{array}{l}\mathrm{TC} \\
(\mathrm{W} / \mathrm{m} \mathrm{K})\end{array}$ & $\begin{array}{l}h_{\mathrm{c}} \\
\left(\mathrm{MW} / \mathrm{m}^{2} \mathrm{~K}\right)\end{array}$ \\
\hline Zhang et al. [33] & $900{ }^{\circ} \mathrm{C}$ and $80 \mathrm{MPa}$ for $30 \mathrm{~min}$ & $\mathrm{~W} / \mathrm{Cu}$-coated diamond & 400 & 55 & 300 & 721 & - \\
\hline Sun et al. [18] & $950{ }^{\circ} \mathrm{C}$ and $60 \mathrm{MPa}$ for $20 \mathrm{~min}$ & $\mathrm{~B}_{4} \mathrm{C}$-coated diamond & 200 & 50 & 1000 & 687 & - \\
\hline $\mathrm{Hu}$ et al. [31] & $950^{\circ} \mathrm{C}$ and $50 \mathrm{MPa}$ for $20 \mathrm{~min}$ & $\mathrm{~B}_{4} \mathrm{C}$-coated diamond & 100 & 60 & 1000 & 650 & 35 \\
\hline Chu et al. [32] & $980^{\circ} \mathrm{C}$ and $42 \mathrm{MPa}$ for $20 \mathrm{~min}$ & $\mathrm{Cu}-1.2 \% \mathrm{Zr}$ powder & 110 & 55 & 320 & 615 & 61 \\
\hline Kang et al. [20] & $1150{ }^{\circ} \mathrm{C}$ and $20 \mathrm{MPa}$ for $10 \mathrm{~min}$ & $\mathrm{Mo}_{2}$ coated diamond & 70 & 60 & - & 596 & - \\
\hline Chu et al. [17] & $950{ }^{\circ} \mathrm{C}$ and $40 \mathrm{MPa}$ for $20 \mathrm{~min}$ & $\mathrm{Cu}-0.8 \% \mathrm{~B}$ powder & 90 & 58 & 283 & 538 & 40 \\
\hline Sinha et al. [34] & $950^{\circ} \mathrm{C}$ and $45 \mathrm{MPa}$ for $30 \mathrm{~min}$ & $\mathrm{Cu}-0.8 \% \mathrm{Cr}$ powder & 110 & 60 & 170 & 601 & 21 \\
\hline
\end{tabular}

"hc" is the interface thermal conductance by calculation 


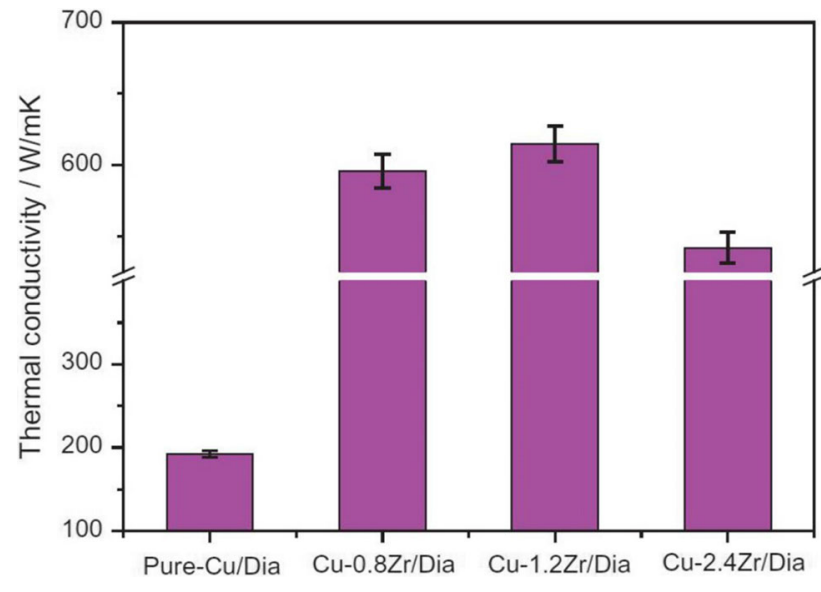

Figure 2 Measured thermal conductivity of $\mathrm{Cu}(\mathrm{Zr}) / \mathrm{Dia}$ composites versus zirconium contents [32].

and $\lambda$ is the thermal conductivity of $\mathrm{B}_{4} \mathrm{C} . R_{\mathrm{Cu} / \mathrm{B} 4 \mathrm{C}}$ and $R_{\mathrm{B} 4 \mathrm{C} / \text { diamond }}$ are the Thermal Boundary Conductance (TBC), which will be addressed thoroughly in "Factors affecting the thermal conductivity of copper/diamond composites" section. This case indicates that the interface thermal conductance comprises two parts: one is the contacted TBC, and the other is the thermal conductance of the interface layer.

The fabricated copper/diamond composites with different metal additives have varied thermal conductivity (see Table 1). Different metal elements have different intrinsic TC, phonon velocity and carbide transformation of interface layers and their solubility in $\mathrm{Cu}$ matrix, which greatly affect the thermal performance of the composites [35]. This finding is also applicable to the studies under the other three processing methods reviewed below.
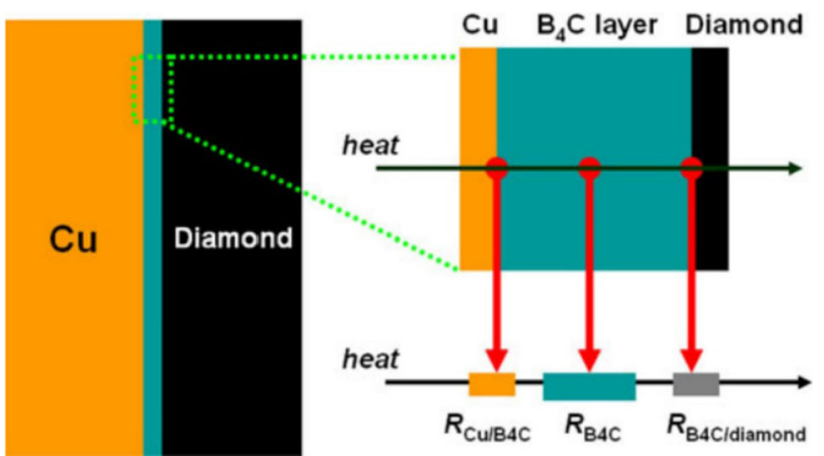

Figure 3 Schematic illustration of the interface thermal resistance of $\mathrm{Cu}-\mathrm{B}_{4} \mathrm{C}$-coated diamond composites according to the concept of an electrical resistance analogy [31].
Most of the copper/diamond composites are fabricated at the temperature below the molten point of copper $\left(1080^{\circ} \mathrm{C}\right.$ ) (see Table 1$)$ via the vacuum hot pressing method, and this is because the pressure can promote the formation of complete interface layers on the diamond particle surfaces while holding the temperature for desired time.

\section{Spark plasma sintering method}

The spark plasma sintering (SPS) method employs a high pulsed DC to heat powder or powder compact fast in an electrically conductive tool under vacuum or inert atmosphere condition, and small uniaxial pressure can be also exerted for densification (the diagram is shown in Fig. 4) [36]. High temperature is generated at the point contact between powder particles, which helps clean and melt the particle surfaces. Sintering necks are formed in a short time, and highly densified billets can be obtained generally.

Effects of $\mathrm{B}, \mathrm{Cr}, \mathrm{Si}, \mathrm{Ti}$ additives on the thermal conductivity of the SPSed copper/diamond composites have been studied (see Table 2). Except for the investigation on the interface layer structure in these studies, the effects of diamond volume fraction are noticed as well. For the fabricated copper/diamond composites with different metal additives added via coating or copper alloying, the results show different correlations. For example, Che finds that the thermal

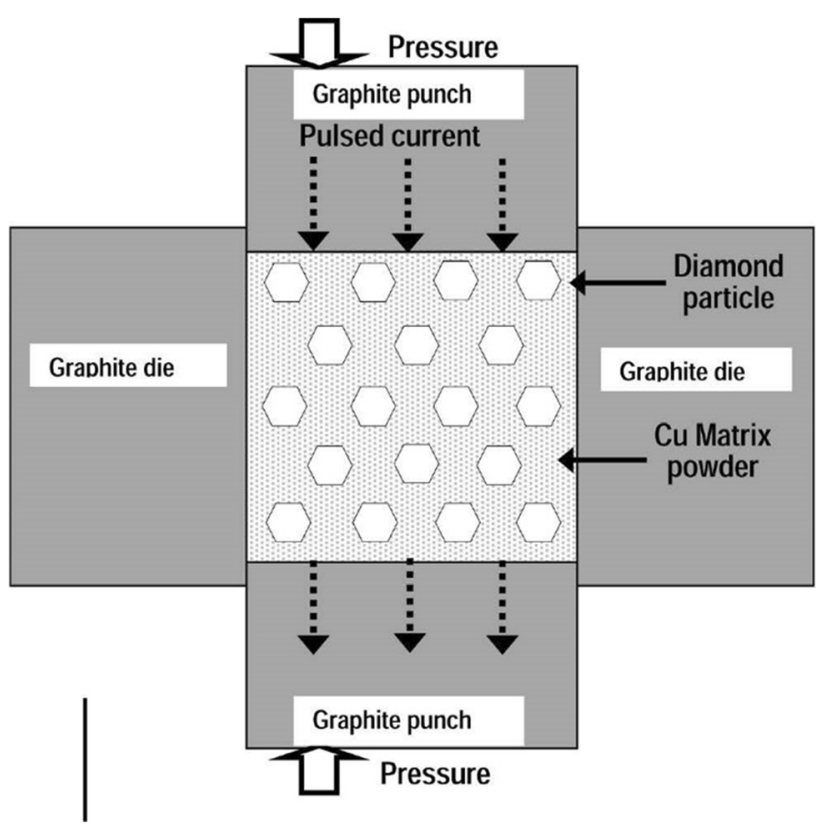

Figure 4 Spark plasma sintering diagram [36]. 
conductivity of the composites with Ti-coated diamond is decreased when the diamond volume fraction is increased, as shown in Fig. 5 [37]. But in Ren's work, the TC of the composites with Cr-coated diamond is increased with increasing the diamond volume fraction from 55 to $70 \mathrm{vol} \%$ [41]. In the case of adding Si-coated diamond, the composites' TC is changed in the way as shown in Fig. 6, when the diamond volume fraction is increased from 40 to $60 \mathrm{vol} \%$ [39].

According to the rule of mixture, a higher diamond volume fraction in the composite should lead to the composite has higher thermal conductivity, because the diamond has very high thermal conductivity (1000-2000 W/m K). However, the composites with too large volume fraction of diamond are usually not easy to be densified during the consolidation process. It's a trade-off between the processing and the proportion of diamond particles. Thus, this is why the thermal conductivity of copper/diamond composites is varied with the diamond volume fraction in the trends shown in Figs. 5 and 6. The optimal thermal conductivity of the composites can be achieved under the combination of high relative density and high diamond volume fraction. Considering the high energy the spark plasma instantly contains, the SPS processing temperature is usually maintained below $1000{ }^{\circ} \mathrm{C}$ for avoiding the damage of diamond particles $[5,42]$.

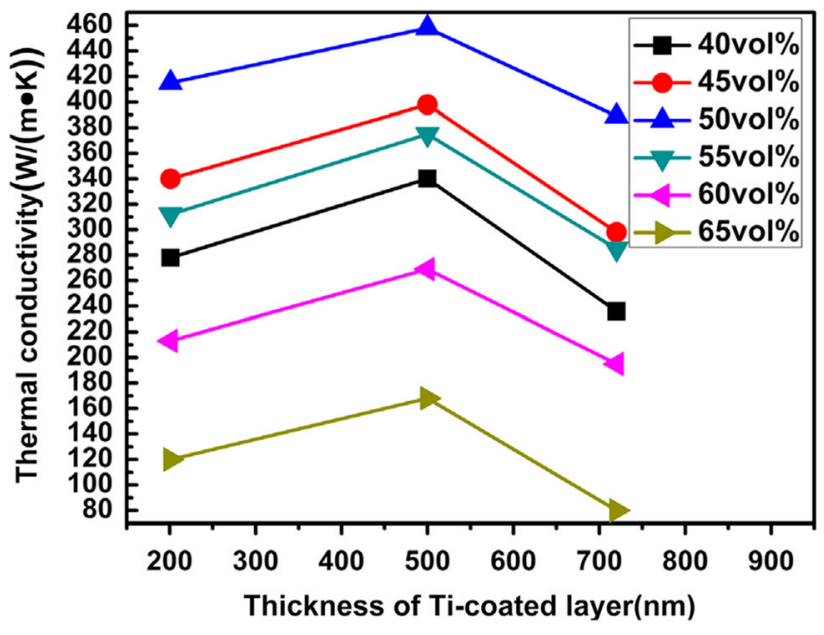

Figure 5 Variation in the thermal conductivity of Ti-coated diamond/ $\mathrm{Cu}$ composites with different volume fractions of diamond with the thickness of the Ti-coated layer on the surface of diamond particles [37].

\section{Metal infiltration method}

In this method, diamond particles are homogeneously distributed in a crucible bottom by vibration first, and then the molten copper with metal additives is poured into the crucible. Low pressure (about a few tens $\mathrm{MPa}$ ) is applied to the composites by pumping in the protected atmosphere in the airtight chamber for achieving densification. The process is illustrated in Fig. 7. Molten copper infiltrates between

Table 2 Thermal conductivity and calculated interface thermal conductance of copper/diamond composites fabricated by the SPS method

\begin{tabular}{|c|c|c|c|c|c|c|c|}
\hline Authors & $\begin{array}{l}\text { Processing } \\
\text { parameters }\end{array}$ & Raw materials & Dia. (um) & $\begin{array}{l}V_{\mathrm{f}} \\
(\%)\end{array}$ & $\begin{array}{l}\text { The thickness of the } \\
\text { interface layer }(\mathrm{nm})\end{array}$ & $\begin{array}{l}\mathrm{TC}(\mathrm{W} / \\
\mathrm{m} \mathrm{K})\end{array}$ & $\begin{array}{l}h_{\mathrm{c}}(\mathrm{MW} / \\
\left.\mathrm{m}^{2} \mathrm{~K}\right)\end{array}$ \\
\hline $\begin{array}{l}\text { Mizuuchi } \\
\text { et al. [36] }\end{array}$ & $\begin{array}{l}900{ }^{\circ} \mathrm{C} 80 \mathrm{Mpa} \\
\text { for } 10 \mathrm{~min}\end{array}$ & $\begin{array}{l}(1.8-13.8 \text { vol\%) B } \\
\text { additive }\end{array}$ & 300 & 50 & - & 689 & - \\
\hline $\begin{array}{l}\text { Grzonka et al. } \\
\text { [24] }\end{array}$ & $\begin{array}{l}900{ }^{\circ} \mathrm{C} 80 \mathrm{Mpa} \\
\text { for } 10 \mathrm{~min}\end{array}$ & $\mathrm{Cu}-0.8$ wt $\% \mathrm{Cr}$ powder & 180 & 50 & - & 589 & - \\
\hline Che et al. [37] & $\begin{array}{l}1000{ }^{\circ} \mathrm{C} 50 \mathrm{Mpa} \\
\text { for } 10 \mathrm{~min}\end{array}$ & $\begin{array}{l}\text { Ti-coated diamond, } \mathrm{Cu}- \\
0.5 \mathrm{wt} \% \mathrm{Ti} \text { alloy }\end{array}$ & 180 & 50 & 500 & 630 & - \\
\hline $\begin{array}{r}\text { Mankowski } \\
\text { et al. [38] }\end{array}$ & $1000{ }^{\circ} \mathrm{C} 50 \mathrm{Mpa}$ & $\mathrm{Cu}-0.8 \mathrm{wt} \% \mathrm{Cr}$ powder & 200 & 50 & - & 658 & - \\
\hline Zhu et al. [39] & $\begin{array}{l}900{ }^{\circ} \mathrm{C} 50 \mathrm{Mpa} \\
\text { for } 3 \mathrm{~min}\end{array}$ & Si-coated diamond & 300 & 50 & - & 535 & - \\
\hline Bai et al. [40] & $\begin{array}{l}1030{ }^{\circ} \mathrm{C} 30 \mathrm{Mpa} \\
\text { for } 6 \mathrm{~min}\end{array}$ & $\mathrm{Cu}-5 \mathrm{wt} \% \mathrm{~B}$ powder & 200 & 44 & - & 660 & - \\
\hline $\begin{array}{l}\text { Rosinski et al. } \\
\text { [9] }\end{array}$ & $\begin{array}{l}900{ }^{\circ} \mathrm{C} 80 \mathrm{Mpa} \\
\text { for } 5 \mathrm{~min}\end{array}$ & $\mathrm{Cu}-5 \mathrm{wt} \% \mathrm{Cr}$ powder & 180 & 50 & $100-200$ & - & - \\
\hline Ren et al. [41] & $\begin{array}{l}950{ }^{\circ} \mathrm{C} 40 \mathrm{Mpa} \\
\text { for } 20 \mathrm{~min}\end{array}$ & Cr-coated diamond & $\begin{array}{l}130 \text { and } 400 \\
\text { blended }\end{array}$ & 70 & $600-900$ & 657 & - \\
\hline
\end{tabular}




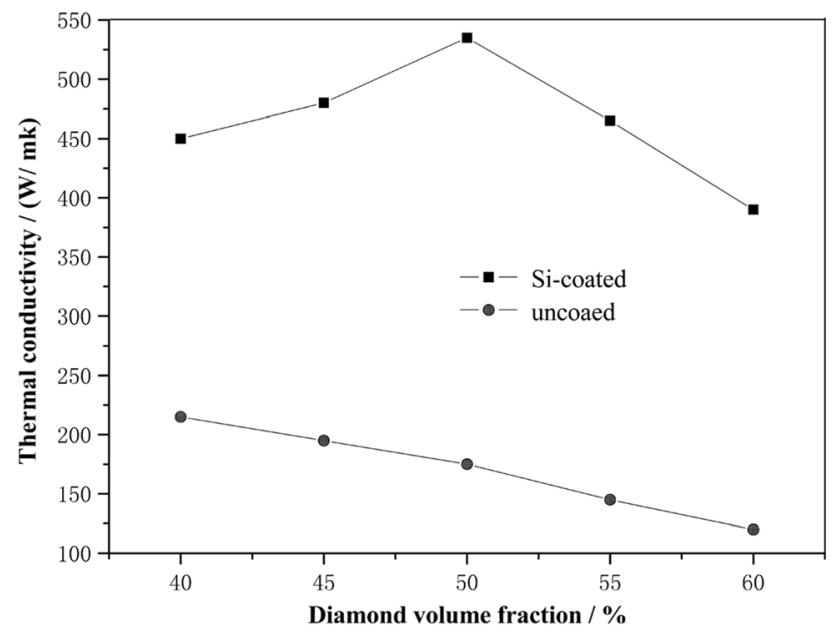

Figure 6 Effect of diamond particle volume fraction on the thermal conductivity of coated and uncoated composites [39].

the diamond particles, and the bulk materials can be obtained after copper is solidified. A detailed discussion of the infiltration mechanism in preparing copper/diamond composites can be found in Refs. $[43,44]$.

We can see that, from Table 3, the high thermal conductivity (up to $900 \mathrm{~W} / \mathrm{m} \mathrm{K}$ ) can be achieved for the copper/diamond composites prepared by this method. This is because high temperature (100-200 ${ }^{\circ} \mathrm{C}$ above the molten point of copper) is beneficial for the diffusion of metal elements. This method is favorable for forming a homogeneous interface layer on the diamond particles and overcoming the poor chemical affinity between the copper and the diamond.

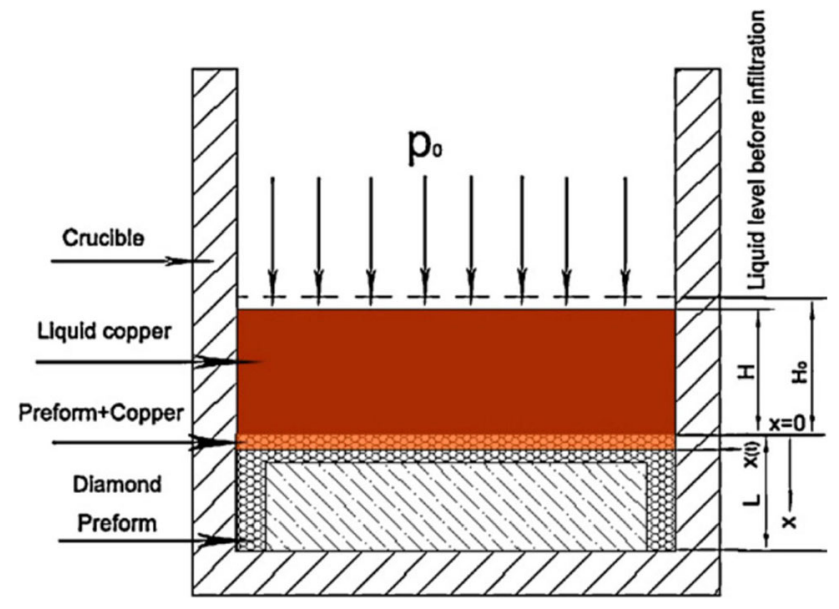

Figure 7 Schematic illustration of the unidimensional infiltration process $[43,44]$.
In Li's work, $\mathrm{Zr}$ element is added in the copper/diamond composites in the way of copper alloying, and he finds that the interface layer's thickness of the composites is varied with adding different amounts of $\mathrm{Zr}$, thus leading to the composite's TC value changed, as shown in Fig. 8 [19]. Based on Differential Effective Model (DEM) calculation, it finds that the composite's TC value has a positive correlation with interface thermal conductance "hc." "hc" is calculated by the models using the TC value of known composites. Interface thermal conductance correlates with the thermal conductivity of the composites positively. It can be reflected by Eqs. (19) and (20) (see "Model prediction of effective thermal conductivity of copper/diamond composites" section).

Bai finds that the thin discontinuous jig saw interface layers formed between the copper and the diamond are more favorable for "hc" than a plain interface layer; the morphology is shown in Fig. 9c. According to the thermal resistance formula, one $R_{\mathrm{Cu} / \text { diamond }}$ item is calculated in this way: $\frac{1}{R_{\text {new }}}=\frac{1}{\mathrm{RC}}+\frac{1}{R_{\mathrm{Cu} / \text { diamond }}} . R_{\text {new }}$ can be taken as the interface thermal resistance (ITR) that is illustrated in Fig. 10b, Rc as ITR that is illustrated in Fig. 10c, and $R_{\mathrm{Cu} / \text { diamond }}$ as the ITR of bare $\mathrm{Cu} /$ diamond interface. In this way, the interface thermal conductance of the jig saw structure shown in Fig. 10b, which is corresponding to the structure in Fig. $9 c$, is larger than that of the planar structure shown in Fig. 10c, which is corresponding to the structure in Fig. 9d. When the morphology of the interface layer is distributed discretely, due to the formation of a new jig saw structure, the value of $R_{\text {new }}$ is smaller than Rc, and the thermal conductivity of the composite would be improved further. Besides, graphite is formed in the interface area under high temperature without adding the $\mathrm{B}$ element, which deteriorates the thermal performance of the composites [50]. Hence, it is necessary to add the appropriate content of carbideforming additives to hinder the formation of graphite.

The effects of diamond volume fraction and processing parameters such as processing temperature and holding time have been also investigated on the copper/diamond composites prepared by the infiltration method, and the primary findings are similar to those of the composites fabricated by VHP and/or SPS methods. We can notice that the most important 
Table 3 Thermal properties of copper/diamond composites fabricated by metal infiltration method

\begin{tabular}{|c|c|c|c|c|c|c|c|}
\hline Authors & Processing parameters & Raw materials & $\begin{array}{l}\text { Dia. } \\
(\mu \mathrm{m})\end{array}$ & $\begin{array}{l}V_{\mathrm{f}} \\
(\%)\end{array}$ & $\begin{array}{l}\text { The thickness of the } \\
\text { interface layer (nm) }\end{array}$ & $\begin{array}{l}\mathrm{TC}(\mathrm{W} / \\
\mathrm{m} \mathrm{K})\end{array}$ & $\begin{array}{l}h_{\mathrm{c}}(\mathrm{MW} / \\
\left.\mathrm{m}^{2} \cdot \mathrm{K}\right)\end{array}$ \\
\hline $\begin{array}{l}\text { Abyzov } \\
\text { et al. [45] }\end{array}$ & $1130{ }^{\circ} \mathrm{C} 10 \mathrm{~Pa}$ for $5 \mathrm{~min}$ & W-coated diamond & 180 & 63 & 150 & 520 & - \\
\hline $\begin{array}{l}\text { Weber et al. } \\
\text { [46] }\end{array}$ & $\begin{array}{l}1180{ }^{\circ} \mathrm{C} 0.6 \mathrm{MPa} \text { for } \\
2 \mathrm{~min}\end{array}$ & $\begin{array}{l}\mathrm{Cu}-1 \% \mathrm{Cr} \text { alloy } \\
\mathrm{Cu}-0.1 \% \mathrm{~B} \text { alloy }\end{array}$ & 200 & 60 & - & $\begin{array}{l}600 \\
700\end{array}$ & - \\
\hline $\begin{array}{l}\text { Dong et al. } \\
\text { [43] }\end{array}$ & $\begin{array}{l}1250-1450{ }^{\circ} \mathrm{C} \text { for } \\
30-150 \mathrm{~min} \text { at vacuum }\end{array}$ & Ti-coated diamond & 110 & - & - & 385 & \\
\hline $\begin{array}{l}\text { Kang et al. } \\
\text { [47] }\end{array}$ & $\begin{array}{l}1150{ }^{\circ} \mathrm{C} 0.6 \mathrm{MPa} \text { for } \\
10 \mathrm{~min}\end{array}$ & $\mathrm{Cr}_{7} \mathrm{C}_{3}$-coated diamond & 70 & 65 & 1000 & 562 & - \\
\hline $\begin{array}{l}\text { Li et al. } \\
{[26]}\end{array}$ & $1150^{\circ} \mathrm{C} 1 \mathrm{MPa}$ for $10 \mathrm{~min}$ & Ti-coated diamond & 70 & 65 & 1292 & 716 & - \\
\hline $\begin{array}{l}\text { Ma et al. } \\
{[48]}\end{array}$ & $\begin{array}{l}1100{ }^{\circ} \mathrm{C} 25 \mathrm{MPa} \text { for } \\
10 \mathrm{~min}\end{array}$ & $\mathrm{Mo}_{2} \mathrm{C}$-coated diamond & $120-150$ & 60 & 500 & 657 & - \\
\hline $\begin{array}{l}\text { Wang et al. } \\
\text { [6] }\end{array}$ & $1150{ }^{\circ} \mathrm{C} 1 \mathrm{MPa}$ for $30 \mathrm{~min}$ & $\begin{array}{l}\mathrm{Cu}-x \mathrm{Cr} \text { alloy and } \mathrm{Cr}- \\
\text { coated diamond }\end{array}$ & $150-180$ & 60 & 500 & 810 & - \\
\hline $\begin{array}{l}\text { Kang et al. } \\
\text { [20] }\end{array}$ & $\begin{array}{l}1150{ }^{\circ} \mathrm{C} 20 \mathrm{MPa} \text { for } \\
10 \mathrm{~min}\end{array}$ & $\mathrm{Mo}_{2} \mathrm{C}$-coated diamond & 70 & 60 & 1000 & 596 & 45 \\
\hline $\begin{array}{l}\text { Li et al. } \\
\text { [19] }\end{array}$ & $1150^{\circ} \mathrm{C} 1 \mathrm{MPa}$ for $10 \mathrm{~min}$ & $\mathrm{Cu}-x \mathrm{Zr}$ alloy & $212-250$ & 61 & 400 & 930 & 80 \\
\hline $\begin{array}{l}\text { Li et al. } \\
\text { [49] }\end{array}$ & $1150^{\circ} \mathrm{C} 1 \mathrm{MPa}$ for $30 \mathrm{~min}$ & $\mathrm{Cu}-x \mathrm{Ti}$ alloy & 230 & 61 & $200-300$ & 752 & - \\
\hline $\begin{array}{l}\text { Bai et al. } \\
{[50]}\end{array}$ & $\begin{array}{l}1150{ }^{\circ} \mathrm{C} 1.5 \mathrm{MPa} \text { for } \\
30 \mathrm{~min}\end{array}$ & $\mathrm{Cu}-x \mathrm{~B}$ alloy & 230 & 67 & 37 & 868 & 90.9 \\
\hline $\begin{array}{l}\text { Jia et al. } \\
{[51]}\end{array}$ & $1350{ }^{\circ} \mathrm{C}$ for $45 \mathrm{~min}$ & W-coated diamond & $150-180$ & 65 & - & 768 & 24.1 \\
\hline Wang [52] & $1150^{\circ} \mathrm{C} 1 \mathrm{MPa}$ for $30 \mathrm{~min}$ & $\mathrm{Cu}-x \mathrm{Zr}$ alloy & $212-250$ & - & 370 & 930 & - \\
\hline
\end{tabular}

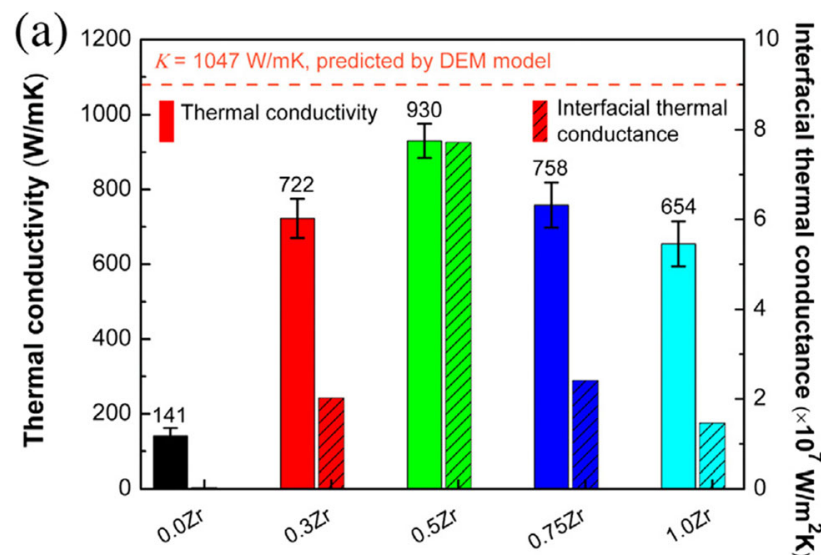

Figure 8 Measured thermal conductivity and interface thermal conductance calculated based on the differential effective medium (DEM) model for $\mathrm{Cu}-\mathrm{Zr} /$ diamond composites [19].

factor, the interface thermal conductance, is not considered (see Table 3) in most of their works. We will discuss this key point in the "Factors affecting the thermal conductivity of copper/diamond composites" section.

\section{High-temperature high-pressure method}

The principle of high-temperature high-pressure (HTHP) method is exerting high pressure and high temperature on the raw mixture materials to fabricate the composite. Usually, the pressure can be up to a few GPa and the temperature is above $1100{ }^{\circ} \mathrm{C}$. Copper/diamond composites processed by this method can be highly densified bulk materials and have a tightly bonded structure between the copper matrix and the diamond particles. Moreover, the HTHP method is capable of fabricating copper/diamond composites with a very high volume fraction of diamond particles up to $90 \mathrm{vol} \%$, which is limited to the former three processing methods we reviewed above. There are only several works reporting the research on copper/diamond composites fabricated by this method (see Table 4). 

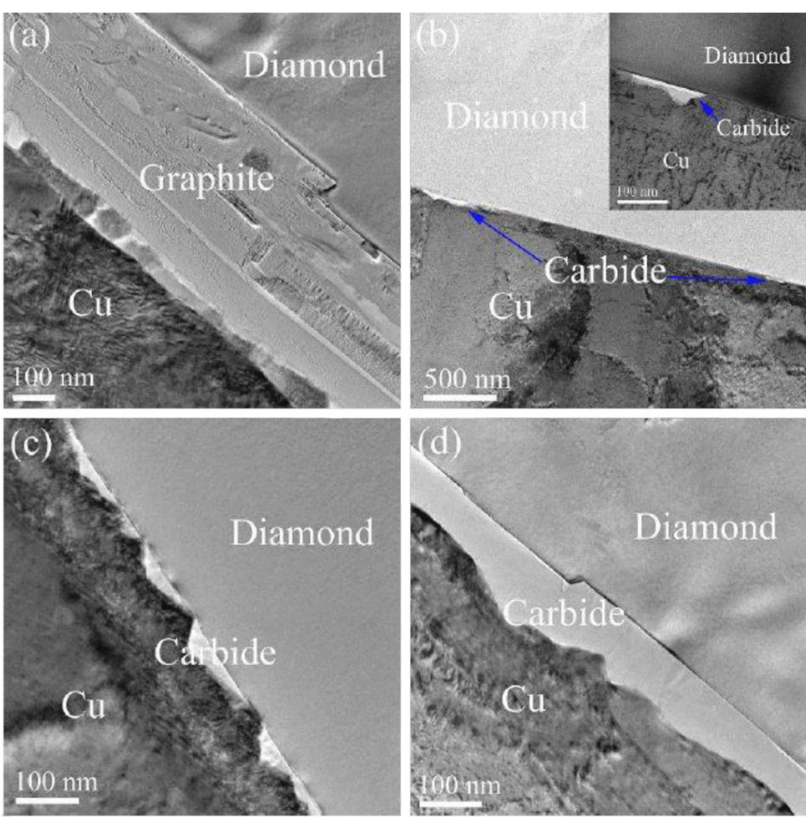

Figure 9 TEM images of the interface structure of $\mathrm{Cu}-$ $x \mathrm{~B} /$ diamond composites: a $\mathrm{x}=0 \mathrm{wt} \%, \quad$ b $\mathrm{x}=0.1 \mathrm{wt} \%$, c $\mathrm{x}=0.3 \mathrm{wt} \%$, and $\mathbf{d} x=1.0 \mathrm{wt} \%$ [50].

Chen et al. find that the thermal conductivity of the HTHP-fabricated copper/diamond composite with carbide-forming element additives like Ti, Co, B, $\mathrm{Zr}$ is two times higher than that of composites from the pure copper and diamond powders [8]. This is because the latter has lower interface thermal conductance than the former. In other words, the carbide layer helps increase the interface thermal conductance.

$\mathrm{HE}$ et al. find that adding different contents of carbide-forming elements like B, $\mathrm{Zr}$ leads to forming a different thickness of interfacial carbide layers in the HTHP-fabricated copper/diamond composites, thus resulting in obtaining different thermal conductivity, as shown in Fig. $11[16,22]$.

$\mathrm{HE}$ et al. used pure copper and diamond powder to fabricate the composites without adding carbideforming elements, and they made a comparison between the HTHP powder metallurgy method and the HTHP infiltration method. The results indicate the samples prepared by the infiltration method can obtain high thermal conductivity of up to 500-700 W/m K. However, the thermal conductivity of the samples fabricated by the powder metallurgy method is quite low. This is because an amorphous carbon layer is formed on the diamond surfaces under such conditions in the HTHP infiltration method, but is not formed by the PM method. The pure amorphous carbon interface layer helps enhance the bonding between copper and diamond particles [53]. The interface characteristics of the samples produced using this method are not well

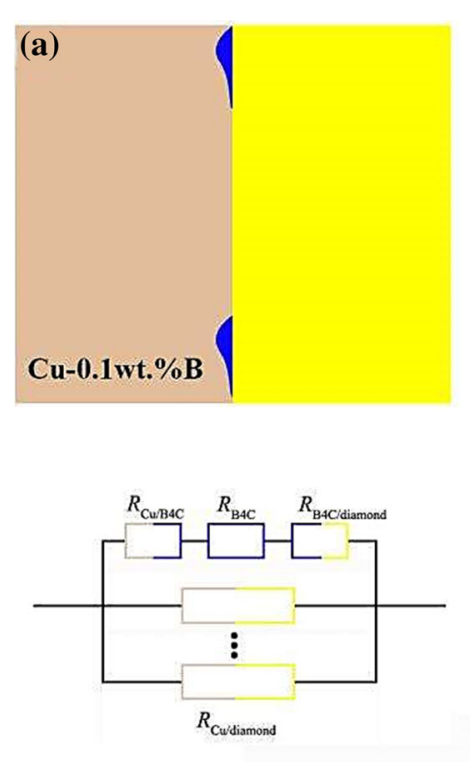

Diamond:
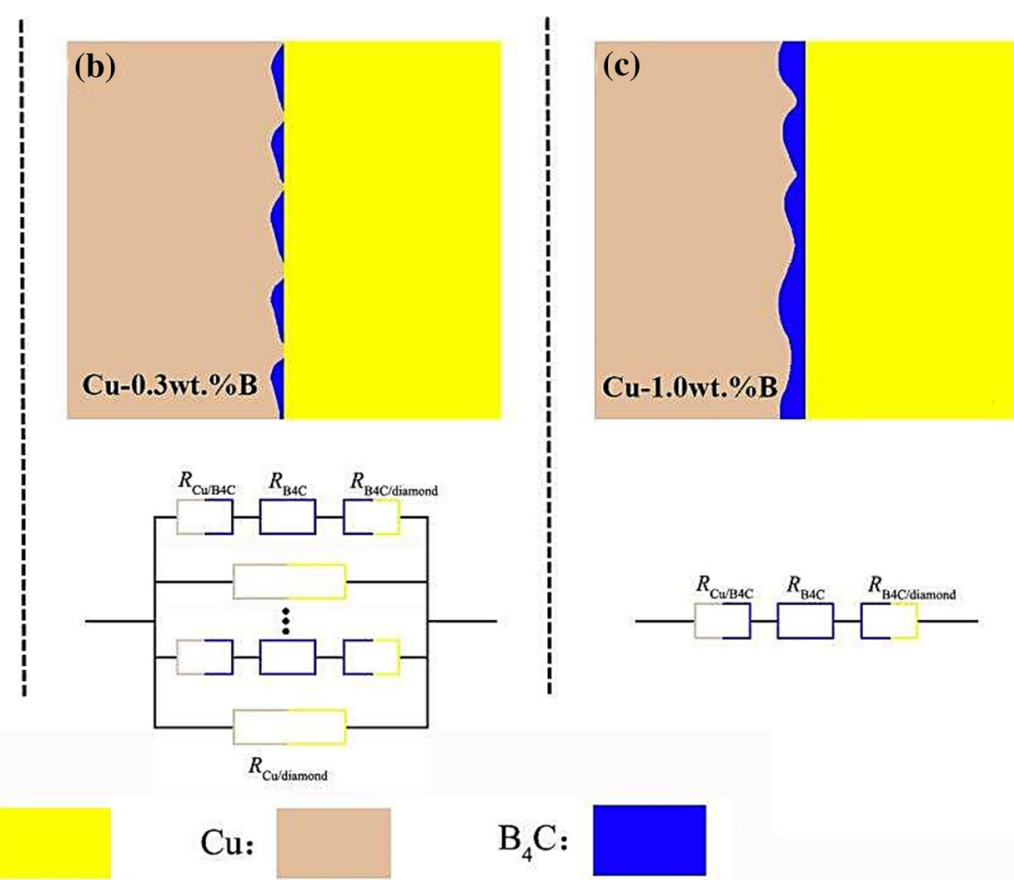

Figure 10 Schematic diagram of interface thermal resistance of $\mathrm{Cu}-x \mathrm{~B} /$ diamond interface: $\mathbf{a}=0.1 \mathrm{wt} \%, \mathbf{b} x=0.3 \mathrm{wt} \%$, and c $x=1.0 \mathrm{wt} \%[50]$. 
Table 4 Thermal properties of copper/diamond composites fabricated by the HPHT method

\begin{tabular}{|c|c|c|c|c|c|c|c|}
\hline Authors & Processing parameters & Raw materials & $\begin{array}{l}\text { Dia. } \\
(\mu \mathrm{m})\end{array}$ & $\begin{array}{l}V_{f} \\
(\%)\end{array}$ & $\begin{array}{l}\text { The thickness of the interface } \\
\text { layer }(\mathrm{nm})\end{array}$ & $\begin{array}{l}\mathrm{TC}(\mathrm{W} / \\
\mathrm{m} \cdot \mathrm{K})\end{array}$ & $\begin{array}{l}\mathrm{h}_{\mathrm{c}}(\mathrm{MW} / \\
\left.\mathrm{m}^{2} \cdot \mathrm{K}\right)\end{array}$ \\
\hline He et al. [22] & $\begin{array}{l}1500^{\circ} \mathrm{C} 5 \mathrm{Gpa} \text { for } \\
10 \mathrm{~min}\end{array}$ & $1 \mathrm{wt} \% \mathrm{Zr}$ powder & 220 & 90 & - & 677 & - \\
\hline $\begin{array}{l}\text { Chen et al. } \\
\text { [8] }\end{array}$ & $\begin{array}{l}1100^{\circ} \mathrm{C} 5 \text { Gpa for } \\
10 \mathrm{~min}\end{array}$ & $\begin{array}{l}\mathrm{Cu}-1 \mathrm{wt} \% \mathrm{Co} \text { alloy } \\
\mathrm{Cu}-0.3 \mathrm{wt} \% \mathrm{~B} \text { alloy } \\
\mathrm{Cu}-0.4 \mathrm{wt} \% \mathrm{Cr} \text { alloy } \\
\mathrm{Cu}-1 \mathrm{wt} \% \mathrm{Ti} \text { alloy }\end{array}$ & $500-600$ & 80 & - & $\begin{array}{l}619 \\
688 \\
683 \\
683\end{array}$ & - \\
\hline $\begin{array}{l}\text { Chen et al. } \\
\text { [53] }\end{array}$ & $\begin{array}{l}1200{ }^{\circ} \mathrm{C} 5.3 \mathrm{Gpa} \text { for } \\
10 \mathrm{~min}\end{array}$ & $\begin{array}{l}\text { Copper and diamond } \\
\text { powder }\end{array}$ & 200 & 60 & - & 207 & - \\
\hline $\begin{array}{l}\text { Ekimov } \\
\text { et al. [54] }\end{array}$ & $\begin{array}{l}1300-2000{ }^{\circ} \mathrm{C} 8 \mathrm{GPa} \\
\text { for the } 20 \mathrm{~s}\end{array}$ & $\mathrm{Cu}-30 \mathrm{wt} \% \mathrm{Ti}$ alloy & 200 & 80 & - & 900 & - \\
\hline He et al. [16] & $\begin{array}{l}1500{ }^{\circ} \mathrm{C} 5 \mathrm{Gpa} \text { for } \\
10 \mathrm{~min}\end{array}$ & $\mathrm{Cu}-0.3 \mathrm{wt} \% \mathrm{~B}$ alloy & 220 & 90 & 2110 & 750 & 20 \\
\hline
\end{tabular}

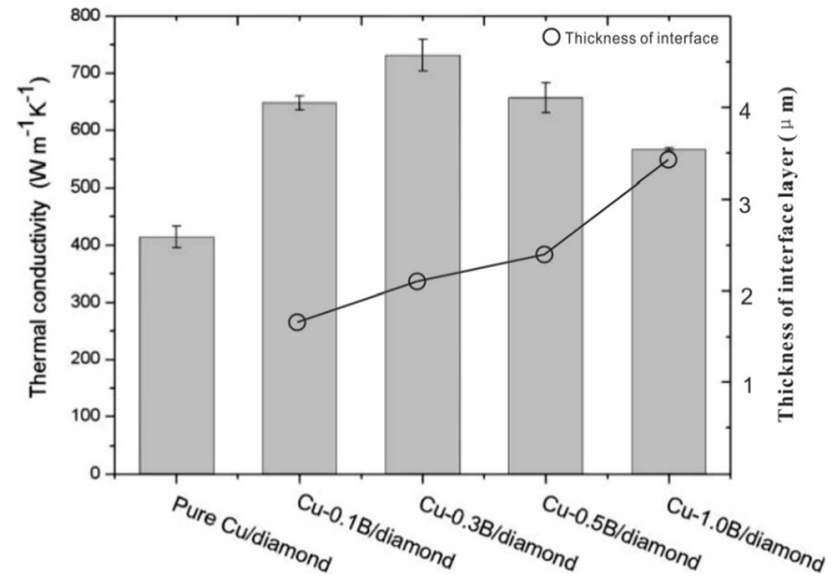

Figure 11 Thermal conductivity and thickness of interface layers measured for the HTHP-fabricated $\mathrm{Cu}-\mathrm{B} /$ diamond [16].

investigated, comparing with that we reviewed above. The high thermal conductivity of copper/diamond composites prepared by the HTHP method could be attributed to the perfect bonding formed between the copper matrix and the diamond particles due to the ultrahigh pressure, as shown in Fig. 12d, e.

\section{Electrodeposition method}

This method utilizes the electrochemical principle to effectively synthesize copper/diamond composites in the specific electrolyte, and the process is illustrated in Fig. 13. The electrodes are usually placed horizontally in the electrochemical solutions, diamond particles are first precipitated on the cathode substrate, and then copper is electrodeposited on the substrate to fill the gap between the precipitated diamond particles, resulting in the formation of a $\mathrm{Cu} /$ diamond composite. Compared to other hightemperature methods we reviewed, this method is conducted at ambient temperature and without pressure in one step, which makes the process simple and cost-effective. Besides, with proper controlling of the synthesizing parameters, copper and diamond can form chemical bonds without carbide-forming additives like other methods. However, this process is still in the early stage [55], and more investigations need to be done to understand the processing. To successfully fabricate a copper/diamond composite with good interface bonding and high thermal conductivity using this method, it needs to appropriately control the parameters such as electric current density, electrolyte types, and solution concentration. The primary processing parameters and thermal conductivity achieved for the fabricated copper/diamond composites are listed in Table 5.

Avrai et al. successfully synthesized copper/diamond composites using the electrodeposition method and the highest thermal conductivity achieved is about $662 \mathrm{~W} / \mathrm{m} \mathrm{K}$ [57]. They demonstrate that this processing method can completely fill the spaces between the precipitated diamond particles and obtain dense composites. They also prove that the current density during the electrodeposition process is under galvanostatic conditions [56]. Hagio et al. find that the $\mathrm{Cu}$ ions in the electrolyte are not easy to concentrate on the surfaces of raw diamond particles compared to SiC-coated diamond, resulting in the 
Figure 12 Micrographs of typical starting diamond powder used (a) and microstructure of the fabricated samples of $\mathrm{Cu}-$ diamond $(\mathbf{b}, \mathbf{c})$ and $\mathrm{Cu}-\mathrm{Ti}-$ diamond (d, e) [54].
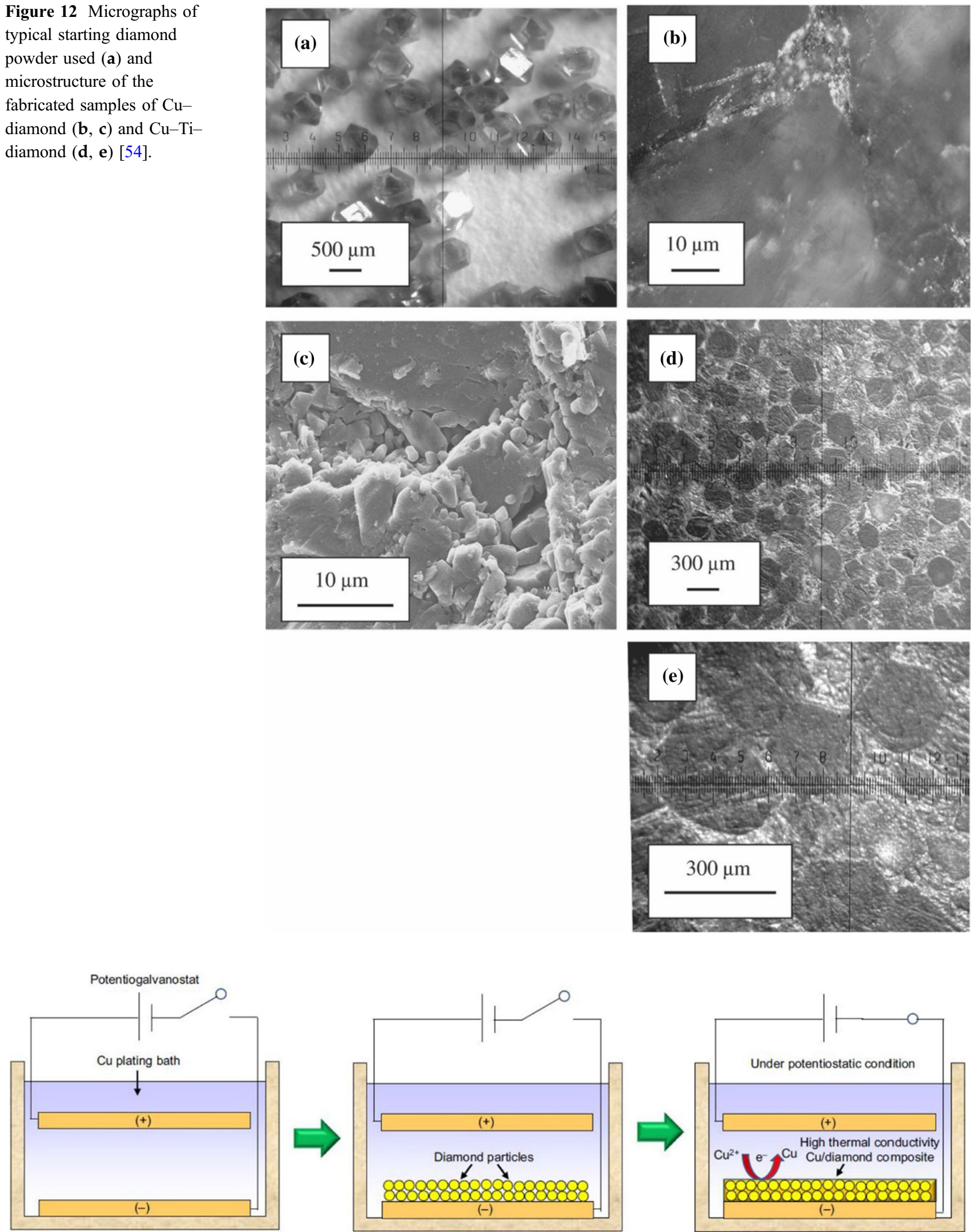

Figure 13 Schematic illustration of the process for fabrication of $\mathrm{Cu}$ /diamond composites using electrodeposition [56].

\section{Springer}


formation of poor interfacial bonding between the copper matrix and the diamond particles [58], and this may be attributed to the low efficiency of electrolysis [59]. $\mathrm{Wu}$ et al. find that two competitive additives ((DVF-B, accelerator, DVF-C, inhibitor) can affect the microstructure, crystallization, interfacial combination of the composite materials [59]. Specifically, DVF-B tends to promote copper fully filling in small and micro intervals formed by diamond particles, while DVF-C prefers to restrain copper deposition in large intervals and leveling copper nodule, and the two competitive additives work cooperatively to form the compactly combined interfaces of $\mathrm{Cu}$-diamond composites. Thus, voids/gaps and nodules can be eliminated in $\mathrm{Cu} /$ diamond composites by adding the two additives in a proper ratio, leading to the well-combined interface and high TC. The specimen synthesized without and with adding these additives is referred to Process- $C$ and ProcessA, respectively, and the corresponding microstructures are shown in Fig. 14. Obviously, good interfacial bonding and flat surface are obtained in the specimen synthesized by Process-A, which would lead to high thermal boundary conductance and thermal conductivity of the composite.

The electric current density is another crucial parameter for optimizing the structure-induced properties. Cho et al. [60] find that inappropriate current density can lead to porosity formation around the TiC-coated diamond particles during the process. As indicated in Fig. 15, the specimen with TiC-coated diamond should have higher thermal conductivity due to the higher thermal boundary conductivity. However, the current density of $50 \mathrm{~mA} / \mathrm{cm}^{2}$ leads to pores formed, because $\mathrm{TiC}$ is electrically conducting, which accelerates the deposition of $\mathrm{Cu}$ from different directions as indicated by the arrows in Fig. $15 \mathrm{~b}$ and easily encloses a porous space. The pores can be eliminated by reducing the electric current density to $12 \mathrm{~mA} / \mathrm{cm}^{2}$, and the resultant thermal conductivity improves to $557 \mathrm{~W} /$ $\mathrm{m} \cdot \mathrm{K}[60]$.

The diamond particle size can affect the electric current density around the diamond particles [55], which further influence the microstructure of fabricated copper/diamond composites. When the diamond particle size is reduced from 420 to $66 \mu \mathrm{m}$, the electrodeposited copper matrix microstructures are changed from large grain/columnar (Fig. 16b) to fine grain/equiaxed (Fig. 16a) [55]. Large diamond particles are not only beneficial to obtain a long heat diffusion length/time in the inside of diamond particles but also improve thermal boundary conductance attributed to larger matrix grains at the vicinity of diamond particles.

\section{Powder forging method}

Compared to other fabrication methods, powder forging can rapidly and cost-effectively prepare

Table 5 Thermal conductivity and calculated interface thermal conductance of copper/diamond composites fabricated by the electrodeposition method

\begin{tabular}{|c|c|c|c|c|c|c|c|}
\hline Authors & $\begin{array}{l}\text { Electric current density } \\
\left(\mathrm{mA} / \mathrm{cm}^{2}\right)\end{array}$ & $\begin{array}{l}\text { Electrolyte and } \\
\text { diamond type }\end{array}$ & $\begin{array}{l}\text { Dia. } \\
(\mu \mathrm{m})\end{array}$ & $V_{\mathrm{f}}(\%)$ & $\begin{array}{l}\text { The thickness of the } \\
\text { interface layer (nm) }\end{array}$ & $\begin{array}{l}\mathrm{TC}(\mathrm{W} / \\
\mathrm{m} \mathrm{K})\end{array}$ & $\begin{array}{l}h_{\mathrm{c}}(\mathrm{MW} / \\
\left.\mathrm{m}^{2} \mathrm{~K}\right)\end{array}$ \\
\hline $\begin{array}{l}\text { Arai et al. } \\
\text { [57] }\end{array}$ & 5 & $\begin{array}{l}\mathrm{CuSO}_{4} \cdot 5 \mathrm{H}_{2} \mathrm{O} \text { and } \\
\mathrm{H}_{2} \mathrm{SO}_{4} \text { solution } \\
\text { Raw diamond }\end{array}$ & 230 & 61 & - & 662 & - \\
\hline $\begin{array}{l}\text { Hagio et al. } \\
{[58]}\end{array}$ & 100 & $\begin{array}{l}\text { Idem } \\
\text { SiC-coated diamond }\end{array}$ & 0.01 & 2.72 & - & 46 & - \\
\hline $\begin{array}{l}\text { Arai et al. } \\
{[56]}\end{array}$ & 5 & $\begin{array}{l}\text { Idem } \\
\text { Raw diamond }\end{array}$ & $10-230$ & 49 & - & 600 & - \\
\hline $\begin{array}{l}\text { Wu et al. } \\
\text { [59] }\end{array}$ & 20 & $\begin{array}{l}\text { Idem + DVF-B and } \\
\text { DVF-C } \\
\text { Raw diamond }\end{array}$ & 100 & 42 & - & 614.87 & - \\
\hline $\begin{array}{l}\text { Cho. et al. } \\
{[55]}\end{array}$ & 50 & $\begin{array}{l}\text { Idem } \\
\text { Raw diamond }\end{array}$ & 66,420 & $\begin{array}{l}42.1 \\
68.2\end{array}$ & - & 222,454 & $1.3,3.1$ \\
\hline $\begin{array}{l}\text { Cho et al. } \\
{[60]}\end{array}$ & 12 & $\begin{array}{l}\text { Idem } \\
\text { TiC-coated diamond }\end{array}$ & 400 & 34.7 & - & 557 & 9.7 \\
\hline
\end{tabular}




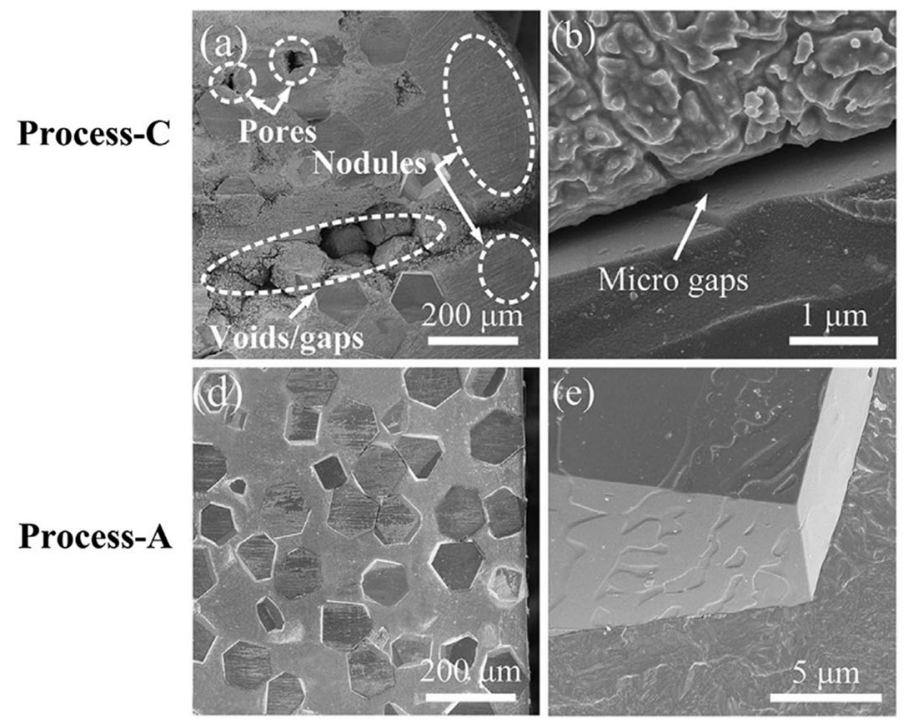

(c)

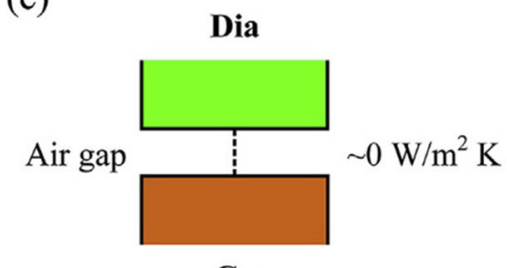

Cu

(f)

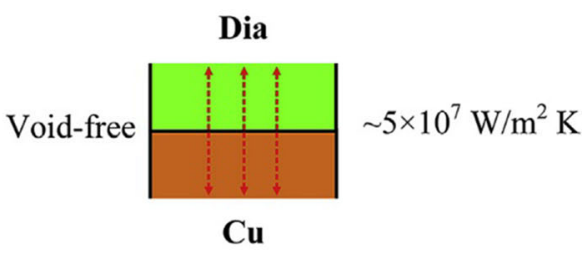

Figure 14 SEM images showing the microstructure of the thick composites: a, b sliced SEM image of process-C composite $(\mathrm{Cu}-$ D-C); c interfacial schematic of $\mathrm{Cu}-\mathrm{D}-\mathrm{C}$ composite; $\mathbf{d}$, e sliced
SEM image of process-A composite $(\mathrm{Cu}-\mathrm{D}-\mathrm{A})$; $\mathbf{f}$ interfacial schematic of $\mathrm{Cu}-\mathrm{D}-\mathrm{A}$ composite [59].
Figure 15 Metal matrix growth during the electrodeposition of composite materials containing a particles that do not conduct electricity (i.e., copper plating with uncoated diamond particles) and $\mathbf{b}$ particles that conduct electricity, which can cause porosity formations during the co-deposition process (i.e., copper plating with TiC-coated diamond particles) [60].
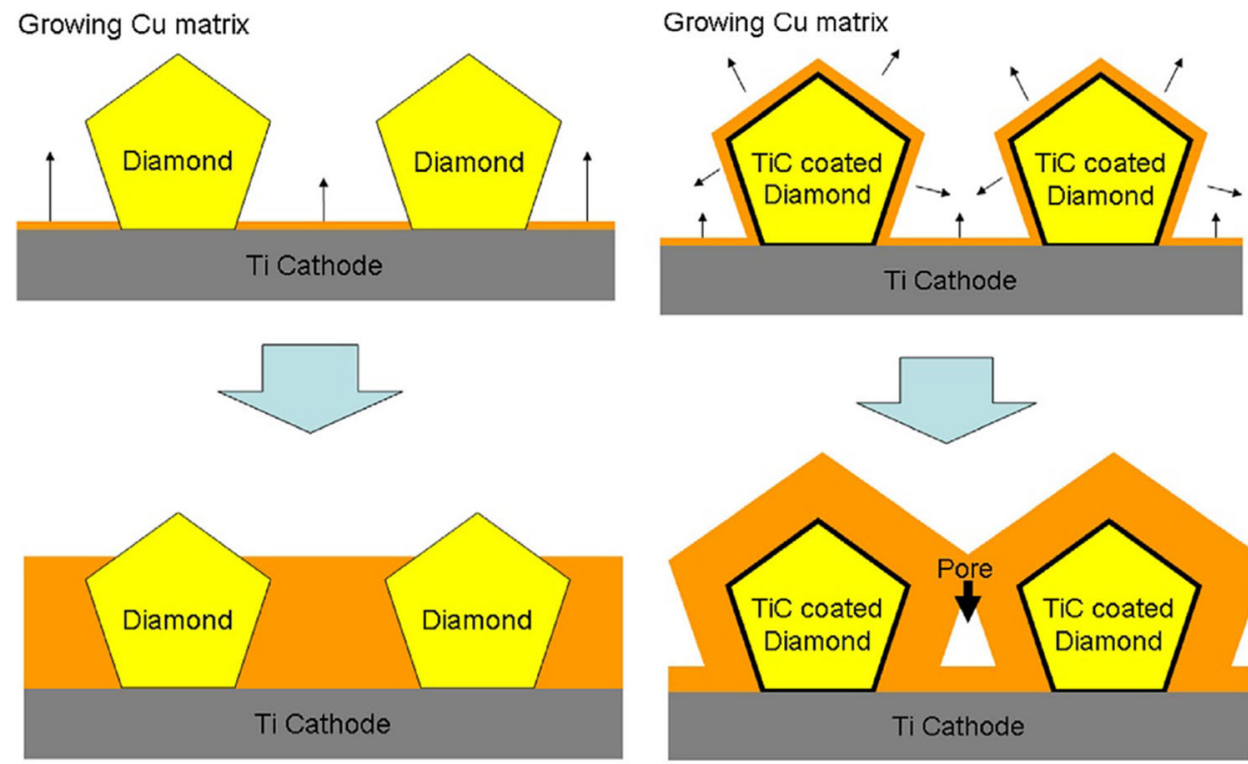

(a)

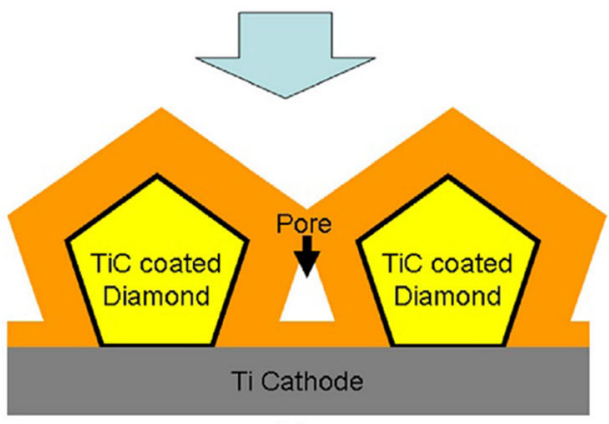

(b) copper/diamond composites without using expensive manufacturing equipment, and it offers an alternative and potentially more effective fabrication method for producing copper/diamond composites. Yang et al. first applied the powder forging technique to producing copper/diamond composites from the powder mixture of artificial diamond and elemental copper powders [61-64]. The carbide-forming elements such as titanium and chromium are introduced in the materials system via adding alloying element powders in the powder mixture or precoated the alloying element on the diamond particle surface. The processing route is shown in Fig. 17, and it primarily includes powder mixing, powder compaction, and then powder forging (heating the compact to the desired temperature in the atmosphere protective chamber using an induction furnace and then forging the hot compact to form a densified copper/diamond composite pancakes/billets). 


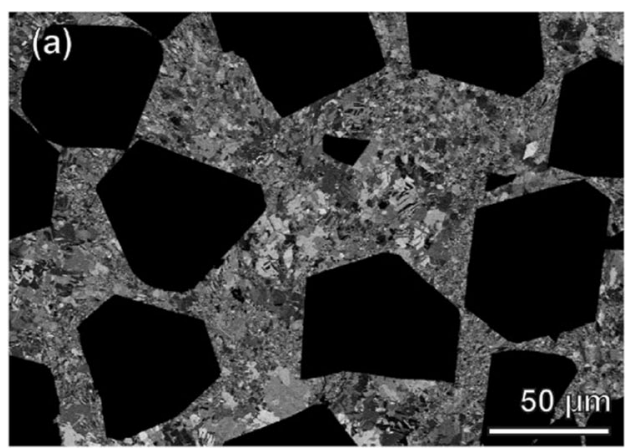

Figure 16 BSE micrographs of copper matrix around a $66-\mu \mathrm{m}$ diamond particles and $\mathbf{b} 420-\mu \mathrm{m}$ diamond particles. Copper grains near $66-\mu \mathrm{m}$ diamond particles are generally small compared to

Yang et al. use the powder forging technique successfully fabricated copper/diamond composites with a diamond volume fraction of up to $65 \mathrm{vol} \%$; however, the copper-55 vol\% diamond composites have much higher thermal conductivity compared to the composite with $65 \mathrm{vol} \%$ of the diamond, attributed to the diamond particles uniformly dispersed in the copper matrix without agglomerations. Through detailed interface characterization and analyses, Yang et al. find that the semi-coherent relationship is established between the interfacial layer (TiC) and the copper matrix, and dispersed nano-spherical particles (TiC) formed on the diamond particles help strengthen the interface bonding between the diamond and the copper matrix. All these characteristics facilitate the heat transfer across the interface layer, contributing to the improvement in thermal conductivity for the forged copper/diamond composites. However, the formation of a thin amorphous carbon

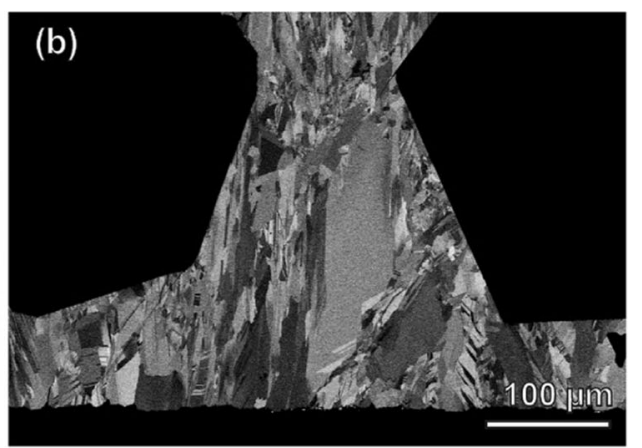

those near $420-\mu \mathrm{m}$ diamond particles. The grains near $420-\mu \mathrm{m}$ diamond particles tend to be columnar, especially near interfaces [55].

layer (for the $1050{ }^{\circ} \mathrm{C}$ forged composite [61]) in the diamond particle (next to the interfacial layer) and deformed structure in the copper matrix have an adverse effect on the thermal conductivity of the formed composites. The hot-forged copper-55 vol\% diamond (coated with $\mathrm{Ti}$ ) composite shows a high thermal conductivity of $550 \mathrm{~W} / \mathrm{m} \cdot \mathrm{K}$ and a CTE of $7 \mathrm{ppm} / \mathrm{K}$ at $313 \mathrm{~K}$, and a flexural strength of $418 \mathrm{MPa}$ [62]. These results are better than those of most reported copper/diamond composites (with the diamond particle size of $<100 \mu \mathrm{m}$ ), suggesting that the powder forging technique is feasible to produce a copper/diamond composite with an acceptable mechanical and thermo-physical performance for practical applications.

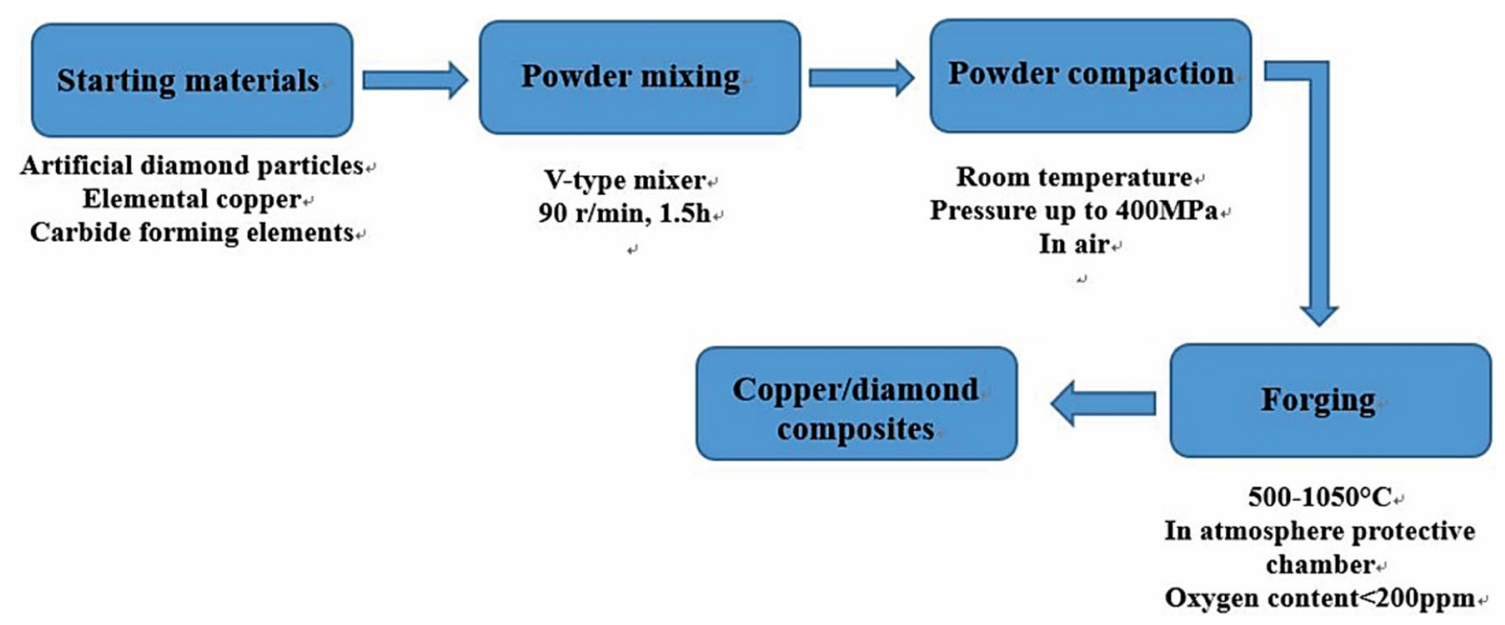

Figure 17 Processing flow chart of fabricating copper/diamond composites by powder forging technique. 


\section{Factors affecting the thermal conductivity of copper/diamond composites}

\section{In copper matrix}

Heat transfers in the materials via heat carriers like atom vibration in the form of phonons or electrons at room temperatures or above. For metal material, the electrons dominate the heat transferring. The defects in the materials such as pores, grain boundaries, and dislocations increase the probability of electron scattering during the transmission process, therefore reducing the overall heat transfer ability $[28,65,66]$. Furthermore, the metal additives used for improving chemical affinity between the copper and the diamond, by forming a carbide interface layer, may form solid solutions with copper. The higher the concentration of metal additives is in the copper matrix, the lower the thermal conductivity of the copper matrix would be. The correlation between $\mathrm{Cr}$ concentration in the copper matrix and the thermal conductivity of the copper matrix is shown in Fig. 18 [46]. The solutes of $\mathrm{Ti}$ and $\mathrm{B}$ in the copper matrix degrade the copper matrix's TC to a different extent $[8,16]$.

\section{In diamond}

Most of the diamond particles used for preparing copper/diamond composites (as reviewed in "Fabrication and thermal conductivity of copper/diamond composites" section) are synthetic single crystal diamond, and its size is in the range of $30 \mu \mathrm{m}$ to $300 \mu \mathrm{m}$. Besides the completeness of diamond particles (the cracks and damaged parts in the diamond particle are treated as defects), the content of nitrogen mainly affects the thermal conductivity of diamond. According to the nitrogen measurement method, the relationship can be expressed in the formula:

$\lambda=2200-3.27[\mathrm{~N}]$

where $\lambda$ is the measured thermal conductivity of diamond and $\mathrm{N}$ represents the nitrogen content $[67,68]$. The higher the nitrogen content is, the lower the thermal conductivity of the raw diamond particles would be.

\section{Interface thermal conductance}

Interface thermal conductance (ITC, "hc" aforementioned in Tables 1, 2, 3, 4, 5), as an indicator,

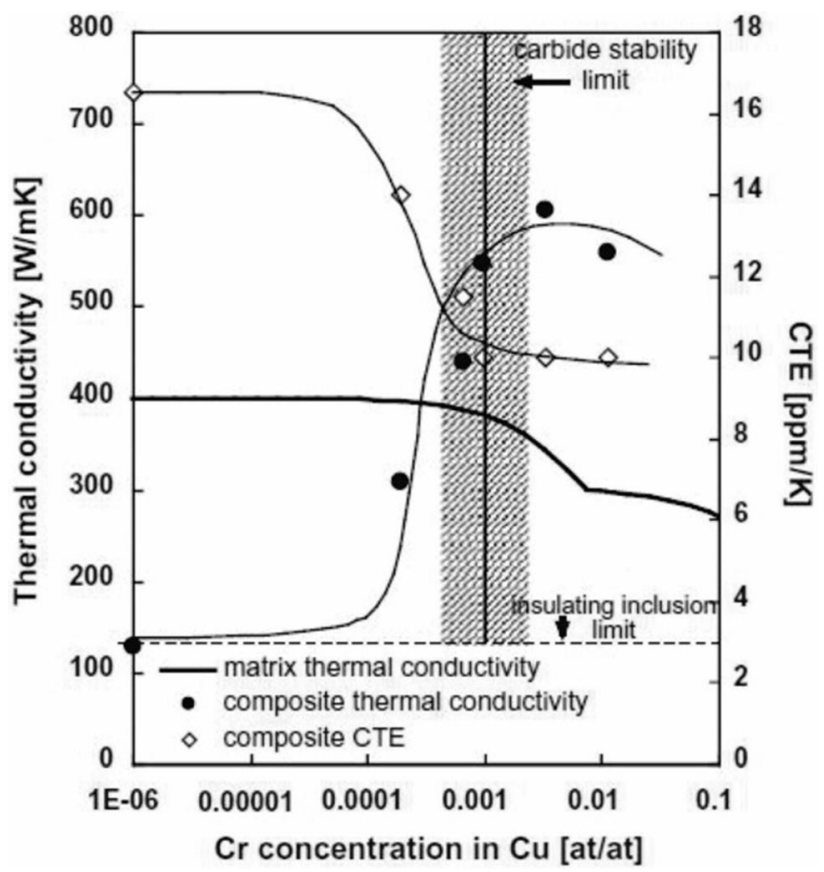

Figure 18 Evolution of thermal conductivity and coefficient of thermal expansion in a $\mathrm{Cu}-\mathrm{Cr} /$ diamond composite as a function of the chromium content in the matrix [46].

determines the ability of heat transferring between the copper matrix and the diamond particles. If the ITC between the copper matrix and the reinforced diamond particles is high, it suggests that the high thermal conductivity of the diamond particles is exploited and the efficiency of heat carriers passing through the "bridge" (interface layer) is high. Otherwise, the thermal conductivity of copper/diamond composites cannot be improved. ITC consists of two parts, thermal boundary conductance (TBC) and thermal conductance of the interface layer, as shown in Fig. 19. $G$ represents TBC and $K$ is the thermal conductivity of the interface layer material.

If the interface layer consists of more than one layer (as shown in Fig. 19), it would complicate the problem in the way that more interface layers with different characteristics of thermal boundary conductance and thermal conductance need to be considered. These two parts are reviewed in sequence as below.

\section{Thermal boundary conductance}

This definition is first appeared in the research on the thermal transfer problem between liquid helium and solids interface under extremely low temperature 


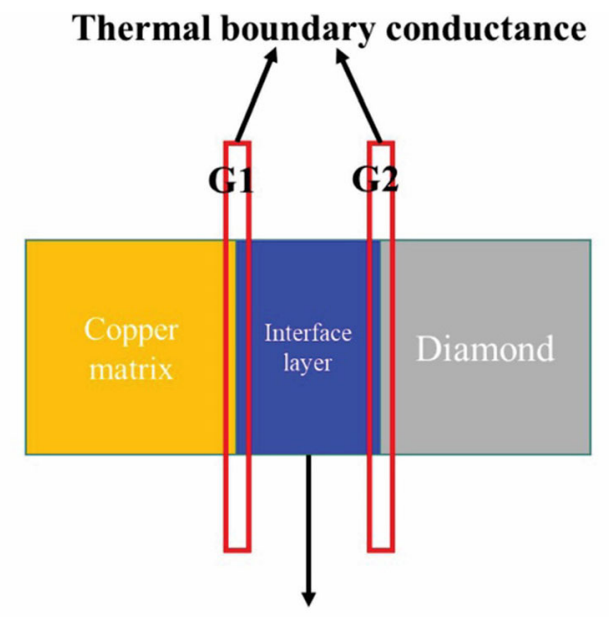

\section{Thermal conductance of the interface layer Kd}

Figure 19 Diagram of interface thermal conductance. G1 and G1 represent TBC of the boundary, respectively; $K_{\mathrm{d}}$ is the thermal conductivity of the material in the interface layer.

(near absolute zero), known as Kapitza resistance [69]. A previous review of this problem can be found in the seminal article authored by Swartz and Pohl [70]. The thermal boundary resistance comes from the experimental observation of the temperature discontinuity when heat flows across the contacted interface. Hence, the mathematical definition of thermal boundary conductance (TBC) is given by:

$G=\frac{Q}{A \times \Delta T}$

where $Q$ is the heat flow, $A$ is the area across the heat flow, and $\Delta T$ is the temperature drop across the boundary. Kapitza resistance, the interface thermal resistance, is the inverse of $G$ in Eq. (2), as expressed in Eq. (1). Recall the physical definition of thermal conductivity, we could find that TBC is the thermal conductivity in unit length by definition. The difference lies in that thermal conductivity is a parameter for bulk materials, whereas TBC is for the boundary without thickness. The mean free path of heat carriers is the determinant for the materials' thermal conductivity, whereas the transmission probability of heat carriers across the boundary is for TBC. This phenomenon is not only found in the helium and solids system but also existed in solid and solid interface [70]. Even for the interface between two identical materials, given the definition above, thermal boundary conductance or nonzero thermal boundary resistance exists. The differences of lattice characteristics and density of states for the materials at the two sides across the boundary lead to the discontinuity of temperature, because of the existence of the interface [27, 71, 72]. In contrast, the identical materials in unit length do not have this problem.

In a common view, electrons are dominant carriers for most of the heat transport in metals while phonons are heat carriers in dielectric and semiconductors at room temperature (above $300 \mathrm{~K}$ ); the thermal transfer problems for copper/diamond composites application in this review are all at room temperature or above [73]. For the cases in copper/diamond composites, the interface may comprise metal/metal, metal/dielectric (diamond), metal/carbide, and carbide/dielectric contacts. The electronic structures of metal carbides such as titanium carbide, chromium carbide are quite complex. For example, chemical bonding in chromium carbides has a complex mixture of metallic, covalent, and ionic characters, and this means both electrons and phonons could participate in the heat transfer process [74-76]. Hence, what matters is the variety of particles that contribute to the thermal transport process across the interface and to quantify and formulate the process. For metal/dielectric and carbide/dielectric contacts, one material is a nonmetal, and the much related research proves phonons are the dominant heat carrier [28, 29, 77-79]. For metal/carbide contact, it is considered as a metal /dielectric problem in many research works. As analyzed above, the induction of electrons adds extra complexity in the case of copper/diamond composites, because of the interaction between phonons and electrons. Many works on copper/diamond composites ignore the contribution of electrons but focus on phonons, and the predictions of thermal conductivity do have discrepancy compared to the experimental results [50, 80]. Sadasivam uses the Atomic green function method and integrates the electron-phonon coupling effect in the function to deal with metal-semiconductor thermal boundary conductance problems [81]. The structure of the semiconductor is as complex as carbide, so we can put it here as a reference for comparison. Although the results from Sadasivam's research are very close to the prediction value by only considering phonons, the contributions of electrons and interaction between electrons and phonons are still worth studying in the future. To identify the heat carrier dominant in the heat transport process across the interface helps us use appropriate theories and 
methods to discuss the problem. From the analyses above, phonons are dominant heat carriers in most cases in the heat transfer process that happened in the copper/diamond composites system.

There are several methods to quantify TBC based on the analysis of phonon characteristics on both sides of the contact. Classical lattice dynamical theory is quite powerful to make prediction; we mainly adopt this perspective to elucidate this problem. The relatively rigorous approaches such as Molecule dynamics simulation and non-equilibrium Green's function method require accurate atomic-level interface boundary information plus huge computational expenses, which are not included in this review but can be found in other works [27, 82-85].

The classical lattice dynamical theory for describing thermal boundary conductance by phonons can be expressed as follows:

$G_{\mathrm{k}}(T)=\frac{1}{V} \int \frac{\partial}{\partial_{T}} \sum_{\mathrm{kj}} \hbar \omega_{\mathrm{kj}} D_{\mathrm{kj}}(\omega) n\left(\omega_{\mathrm{kj}}, T\right) v_{\mathrm{kj}} \alpha_{\mathrm{kj}} \mathrm{d} \omega$

where subscripts $\mathrm{k}$ and $\mathrm{j}$ mean phonon wave vector and phonon mode, respectively, $\omega_{\mathrm{kj}}$ is the phonon angular frequency, $D_{\mathrm{kj}}(\omega)$ is the phonon density of states, $v_{\mathrm{kj}}$ is the component of phonon group velocity for the interface, $n\left(\omega_{\mathrm{kj}}, T\right)$ is the Bose-Einstein distribution function, $V$ is the volume of the object. This formula is constructed based on the Landauer theory [82]. This formula means that phonons in the first Brillouin zone with $v_{\mathrm{kj}}$ velocities transmit through the boundary with the transmission probability of $\alpha_{\mathrm{kj}}$. The subscripts $k$ and $j$ are phonon wave vector and polarization, respectively. Thus, the thermal boundary conductance $G$ can be calculated by the integral of $G_{\mathrm{k}}$ over all of the allowed phonon wave vectors and polarizations. Within this expression, the distinction among the models introduced next lies in the transmission coefficient parameter $\alpha_{\mathrm{kj}}$.

(A) Acoustic mismatch model Acoustic mismatch model theory (AMM) is based on the following assumptions:

(1) The interface is a perfectly specular plane, phonons incident on the interface are either refracted or reflected, according to the critical angles which are decided by Snell's law [70], and any elastic and/or inelastic scattering behaviors are ignored;
(2) Transmission coefficients are determined by the difference of sound velocities and materials density of materials on the two sides across the boundary; one classical formula is given:

$\alpha_{\mathrm{kj}}=\frac{4 Z_{\mathrm{A}} Z_{\mathrm{B}}}{\left(Z_{\mathrm{A}}+Z_{\mathrm{B}}\right)^{2}}$

where subscripts $A$ and $B$ represent the two sides across the boundary; $Z$ is acoustic impedance given by the product of material mass density and sound velocity lying on that side; and

(3) Phonon frequency $\omega_{\mathrm{kj}}$ on the side A can only couple with the phonon on the side B with the same frequency; this confines that there are limited phonons that can be transmitted through the interface; especially, the phonon density of states on the two sides is highly mismatched.

The thermal boundary conductance under the AMM case could be calculated by integrating Eq. (3) substituting $\alpha_{\mathrm{kj}}$ by Eq. (4) within certain angles (which are decided by assumption (1)). AMM has been proved that the prediction result has good agreement with the experimental data below a very low temperature, about $30 \mathrm{~K}$. This is because highfrequency modes of phonons that participate in the thermal transfer process are not considered by AMM. There are many works about copper/diamond composites we reviewed above to use AMM methods to calculate the thermal boundary conductance $[16,19,20,86]$. The predictions do have large discrepancies compared to the experimental results. By putting the predicted TBC value in the effective models to calculate the thermal conductivity of copper/diamond composite, which will be reviewed in the following section, the predicted composite's thermal conductivity is comparable with the experimental measurements. This is an indirect method to verify the effectiveness of the AMM model. In another work [87], authors directly compared the prediction values by AMM to the experimentally measured TBC value by TDTR technique (which will be introduced later), and it clearly shows the discrepancy between the predicted and experimental values. This means the assumptions in AMM theory need to be further refined. 
(B) Diffuse mismatch model The diffuse mismatch model (DMM) is based on different assumptions about how phonons carry heat energy transmitted through the interface, comparing the AMM. Swartz first introduces the concept by assuming that all the phonons are diffusely scattered across the interface [79], not like the case in AMM that only phonons within certain velocity angles can pass. The main assumption is that the maximum frequency is the cutoff frequency of materials with the lower Debye temperature side and phonon frequency $\omega_{\mathrm{kj}}$ on side 1 (A) can only couple with the phonon on side 2 (B) with the same frequency. As mentioned before, the only difference between these models lies in transmission probability $\alpha$ (because the phonon energy $\hbar \omega$ is independent of its directions and modes). In the DMM model, the transmission probability follows:

$\alpha_{i}(\omega)=1-\alpha_{3-i}(\omega)$

where $i$ can take 1 and $2 . \alpha_{i}(\omega)$ represents transmission probability from the side $i ; 1-\alpha_{3-i}(\omega)$ is the reflection probability from the other side. Equation (5) indicates transmission probability from side 1 (A) equals reflection probability of side 2 (B) and vice versa. Heat flux from the side $i$ can be expressed as the number of phonons with energy $\hbar \omega$ leaving:

$\sum_{j} \int_{0}^{2 \pi} \int_{0}^{\pi / 2} \mathrm{~d} \theta \cos \theta \mathrm{d} \phi v_{i, j} D_{i j}(\omega) n(\omega, T) \alpha_{i}(\omega)$

Since it is independent of angles, Eq. (6) becomes:

$\frac{1}{4} \sum_{j}\left[D_{i j}(\omega) n(\omega, T)\right] \alpha_{i}(\omega)$

Heat flux on the two sides across the interface should be equal; based on this, we get:

$\sum_{j} v_{i, j} D_{i j}(\omega) n(\omega, T) \alpha_{i}(\omega)=\sum_{j} v_{3-i, j} D_{3-i, j}(\omega) n(\omega, T)\left[1-\alpha_{i}(\omega)\right]$

Thus, we can have $\alpha_{i}(\omega)$ :

$\alpha_{i}(\omega)=\frac{\sum_{j} v_{3-i, j} D_{3-i, j}(\omega)}{\sum_{i, j} v_{i, j} D_{i j}(\omega)}$

The thermal boundary conductance under the DMM model then can be calculated by replacing $\alpha_{i}(\omega)$ in Eq. (3) with Eq. (9).
(C) TBC across the metal-metal contacts by electrons When the electrons are dominant as heat carriers across the metal-metal boundary, some descriptions in Eq. (3) are changed, but the principle is preserved. The model can be formulated as:

$G_{e, 12}=\frac{1}{4} \int_{0}^{\infty}\left(\varepsilon-\varepsilon_{F, 1}\right) D_{1}(\varepsilon) \frac{\partial f_{1}}{\partial T} v_{F, 1} \zeta_{12} \mathrm{~d} \varepsilon$

where $G_{e, 12}$ represents the electron thermal boundary conductance across the metal 1 (A) and metal 2 (B), $\varepsilon$ and $\varepsilon_{\mathrm{F}, 1}$ are electron energy and Fermi energy of the metal $1(\mathrm{~A}), D_{1}(\varepsilon)$ is the density of state, $\mathrm{f}$ is the Fermi-Dirac distribution function in contrast with that of phonons, $v_{\mathrm{F}, 1}$ is Fermi velocity, and $\zeta_{12}$ is the transmission coefficient. Still, transmission probability is the parameter that needs to be calculated. Some researchers find that assuming electrons transfer across the boundary diffusively can make the prediction and experimental results consistent [88, 89]. Similar to the process for solving the transmission coefficient in the last section "Diffuse mismatch model," we have:

$$
\begin{aligned}
\int_{0}^{\infty} & \left(\varepsilon-\varepsilon_{\mathrm{F}, 1}\right) D_{1}(\varepsilon) f_{1} v_{\mathrm{F}, 1} \zeta_{12}(\varepsilon) d \varepsilon \\
= & \int_{0}^{\infty}\left(\varepsilon-\varepsilon_{\mathrm{F}, 2}\right) D_{2}(\varepsilon)\left(1-f_{2}\right) v_{\mathrm{F}, 2} \zeta_{21}(\varepsilon) \mathrm{d} \varepsilon
\end{aligned}
$$

Then, for approximation, based on the assumptions of (1) electrons on both the metal sides have the same Fermi energy and (2) energy after transmission will not change; we get the formula of $\zeta_{12}(\varepsilon)$ :

$\zeta_{12}(\varepsilon)=\frac{D_{2}(\varepsilon)\left(1-f_{2}\right) v_{\mathrm{F}, 2}}{D_{1}(\varepsilon) f_{1} v_{\mathrm{F}, 1}+D_{2}(\varepsilon)\left(1-f_{2}\right) v_{\mathrm{F}, 2}}$

Because the results at room temperature are of our interests, by substituting the $\zeta_{12}(\varepsilon)$ in Eq. (10) with Eq. (12), the final $G_{e, 12}$ can be expressed as:

$G_{e, 12}=\frac{1}{4} \frac{\gamma_{1} v_{\mathrm{F}, 1} \gamma_{2} v_{\mathrm{F}, 2}}{\gamma_{1} v_{\mathrm{F}} 1+\gamma_{2} v_{\mathrm{F}} 2} T$

where $\gamma$ is the coefficient of electron heat capacity. Details on the derivation of this result can be found in Refs $[89,90]$.

(D) Factors influencing TBC The characteristics of the boundary between the two materials affect the thermal boundary conductance.

(1) Roughness

Experiments conducted by Patrick's group demonstrate that the thermal boundary conductance 
is decreased with the increasing roughness of $\mathrm{Si}$ substrate coated with $\mathrm{Al}$ thin film (as shown in Fig. 20) [91]. The DMM modeling curve in Fig. 20 is derived from Eq. (3), but the roughness factor is introduced into Eq. (3) in the way formulated in the research work [92], and the calculated results align well with the experimental data that are measured by time-domain thermo-reflectance (TDTR) method. The roughness can be regarded as defects in the lattices and arouses phonon scattering, and the decrease in boundary roughness helps improve the TBC, as suggested in Fig. 20.

Regardless of the silicon roughening procedure (indicated in the plot), the thermal boundary conductance follows a similar relationship with RMS roughness as shown in Fig. 20. The accuracy of the AFM (atomic force microscope) tip is only about $10 \mathrm{~nm}$, and this may lead to limitation and deviation for the measurement, thereby affecting the final results [28].

When the length scale of the roughness is larger, the tendency could be different. Researchers try to increase the interfacial contacting area by etching the diamond surface to form a zigzag structure [94], as shown in Fig. 21a, b, and they find that the etched structure could improve the efficiency of the thermal energy transmission. This is because the etched surface could absorb the reflected energy wave (phonons and electrons) many times (as indicated in Fig. 21e), resulting in doubly or more efficient heat transfer and

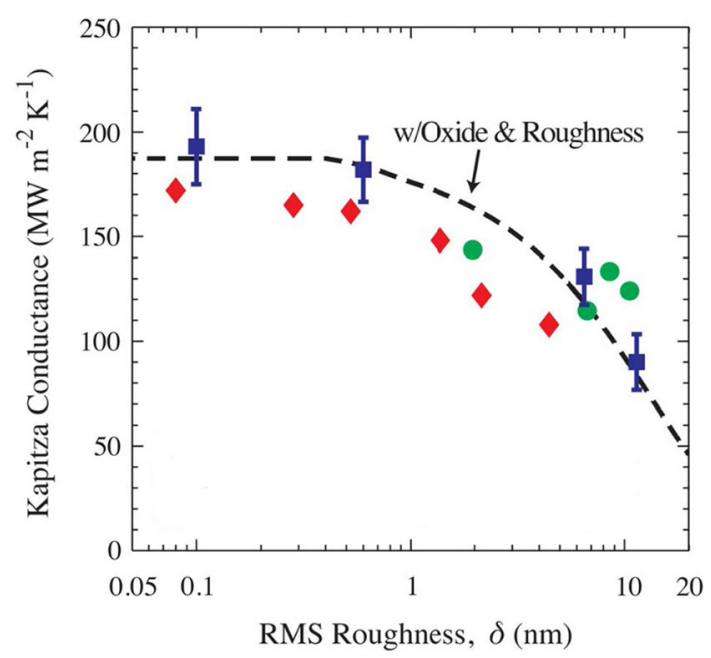

Figure 20 Room-temperature predicted (line) and measured thermal boundary conductance et al./Si interfaces plotted as a function of interface roughness [91]. Blue dot data are from [91]. Red dot data are from [92], Green dot data are from [93]. higher thermal TBC compared to that of un-etched surface [94]. Moreover, the formation of Si nanopillars on the Si surface, as illustrated in Fig. 22, can also enhance the TBC between $\mathrm{Si}$ and $\mathrm{Al}$ [95]. Compared to the planar surface, the rough surface caused by the formed nanopillar has a larger effective contact area, contributing to the significant increase in TBC up to 90\% [95].

(2) Atomic intermixing

The assumption of an atom sitting on the two sides of the interface which can be contacted without mixing is a perfect situation. When several layers of atom diffuse across the interface boundary to form an intermixing layer; it can affect the thermal transfer process and TBC. One study investigates the intermixing thickness of $\mathrm{Cr} / \mathrm{Si}^{\prime} \mathrm{s}$ effect on thermal boundary conductance from both experimental and calculation perspectives, and it finds that TBC decreases with an increase in the thickness of the intermixing layer [96]. Figure 23 indicates the predicted results obtained from the modified DMM model have good agreement with the experimental data. The principle of DMM modification is to add a coefficient about the interfacial mixing layer in Eq. (3), and the details can be found in Ref [96], and this applies to the metal/metal interface [89].

(3) Interfacial bonding strength

Both the interfacial mechanical bonding and chemical bonding affect the TBC. In general, there is a positive correlation between interfacial bonding strength and TBC. Mechanical bonding in the interface area is a kind of physical contact bonding

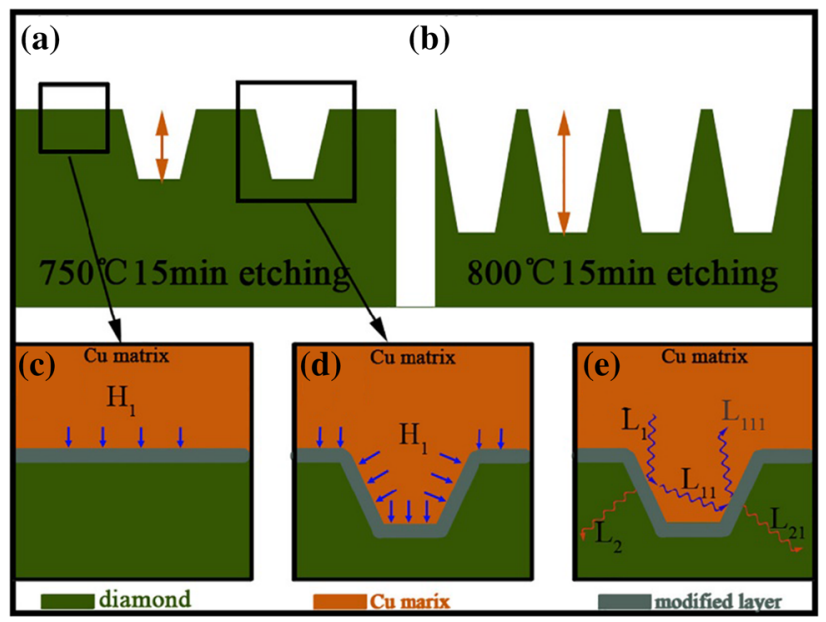

Figure 21 Schematic diagram of etching pits and interfacial heat flux: a, b etching and interface coupling area; c flat interface, d rough interface, e single coupling at the pits [94]. 

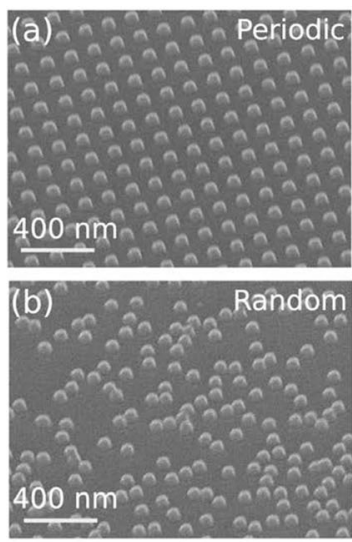

(c)

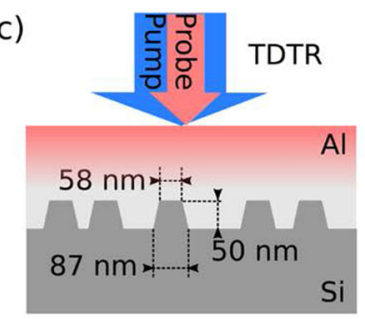

(d)

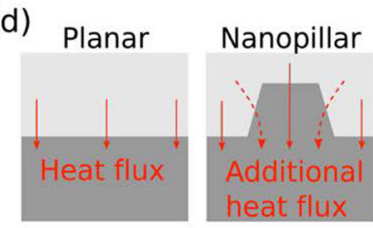

(e)

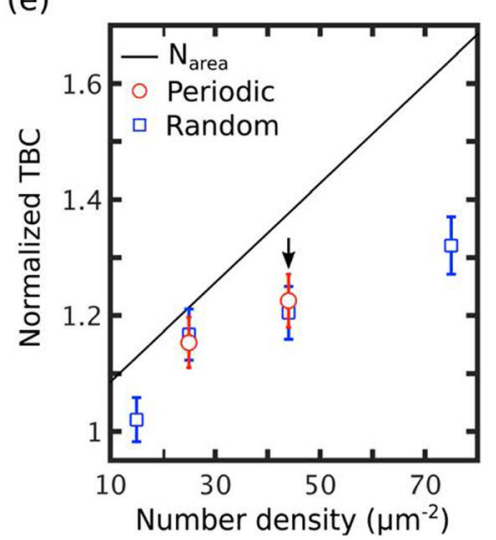

Figure 22 SEM images of $\mathbf{a}$ periodic and $\mathbf{b}$ random nanopillars fabricated on $\mathrm{Si}$ substrates using EBL, c schematic of a nanostructured Si surface capped with a 100-nm Al layer as the TBC is being monitored by TDTR, $\mathbf{d}$ schematic illustration of thermal transport enhancement by a nanopillar in comparison with

without forming chemical bonds between the two phases. Strong mechanical bonding usually exhibits higher TBC. As shown in Fig. 12e, the copper/diamond composite fabricated by the HPHT method has tight interface bonding, which leads to the composite has higher thermal conductivity. Yang et al. also find that the nano-spherical TiC particles grown on the diamond surfaces can enhance the interlocking with copper matrix (Fig. 24a), thus increasing the interfacial bonding strength, and this is more beneficial for obtaining high TBC compared to the planar TiC interface layer in Fig. 24b [62].

The strength of chemical bonding is usually much higher than mechanical bonding; however, copper has a poor chemical affinity with the diamond

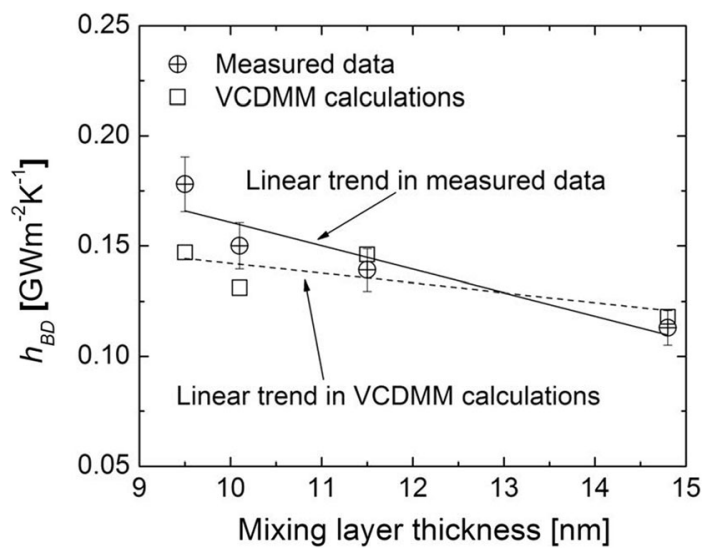

Figure 23 Comparison of the VCDMM to the experimental data on samples $\mathrm{Cr} / \mathrm{Si}$ with different interfacial mixing thicknesses [96]. the case of a planar interface (dotted lines indicate that heat can also pass through the sidewall of the nanopillar to cross the interface) and e normalized TBC as a function of the number density of nanopillars for the periodic (circle) and random (square) nanostructured $\mathrm{Si} / \mathrm{Al}$ interfaces [95].

surface, making it hard to form efficient bonding between. Two ways have been used to facilitate the formation of effective chemical bonding between the copper and the diamond. One is forming the carbide layer between the copper matrix and diamond particles, which has been reviewed in "Fabrication and thermal conductivity of copper/diamond composites" section. In this way, the carbide layer has strong chemical bonding with diamond, and the chemical affinity between the copper and the metal carbides is better than that between copper and diamond $[19,97]$. The other one is by modifying the surface chemistry. Mark finds that the transition from van der Waals to covalent bonding increases the ITC by $\sim 80 \%$ after the $\mathrm{Au} / \mathrm{Qz}$ interface is chemically modified, as shown in Fig. 25 [98], demonstrating that the increased interfacial chemical bonding can increase the TBC because of the covalent bonding is stronger than van der Waals. Hopkins finds that the graphene surface that is functionalized by Ar:O can boost the TBC between the graphene and $\mathrm{Al}$, and this is because the two electrons of $\mathrm{O}$ can form covalent bonding and combine with $\mathrm{Al}$, respectively [99].

The interfacial bonding strength is hard to measure directly, due to its small scale in the composite materials. Many related research works combine mechanical properties and fractography around the reinforcement of the composites to assess the interfacial bonding [100-102]. For example, Wu et al. derive an equation to evaluate the interfacial bonding energy theoretically [103], which is expressed as: 
Figure 24 Sketch of toughening and reinforcing mechanisms for a $800-\mathrm{Cu} /$ 55Dia composite and b $1050 \mathrm{C}-\mathrm{Cu} / 55 \mathrm{Dia}$ composite; and schematic illustration of heat transport in c $800 \mathrm{C}-\mathrm{Cu} / 55 \mathrm{Dia}$ composite and $\mathbf{d} 1050-\mathrm{Cu} / 55 \mathrm{Dia}$ composite [62].

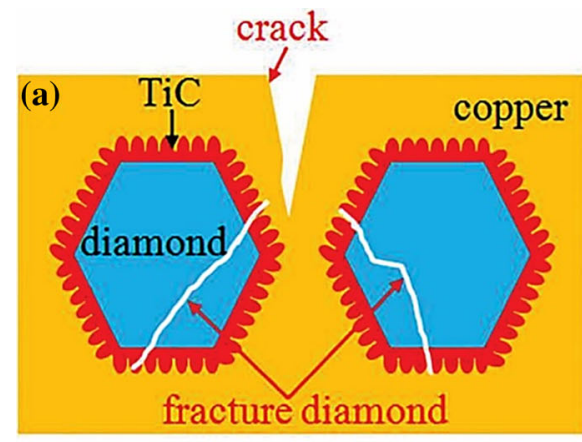

mechanical interlock



smooth

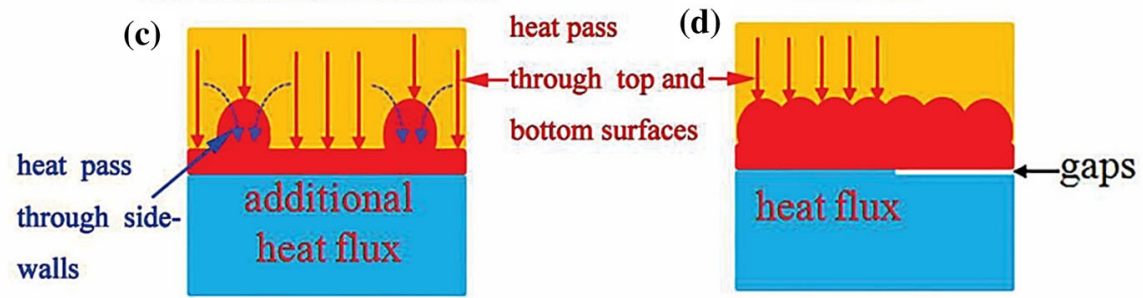

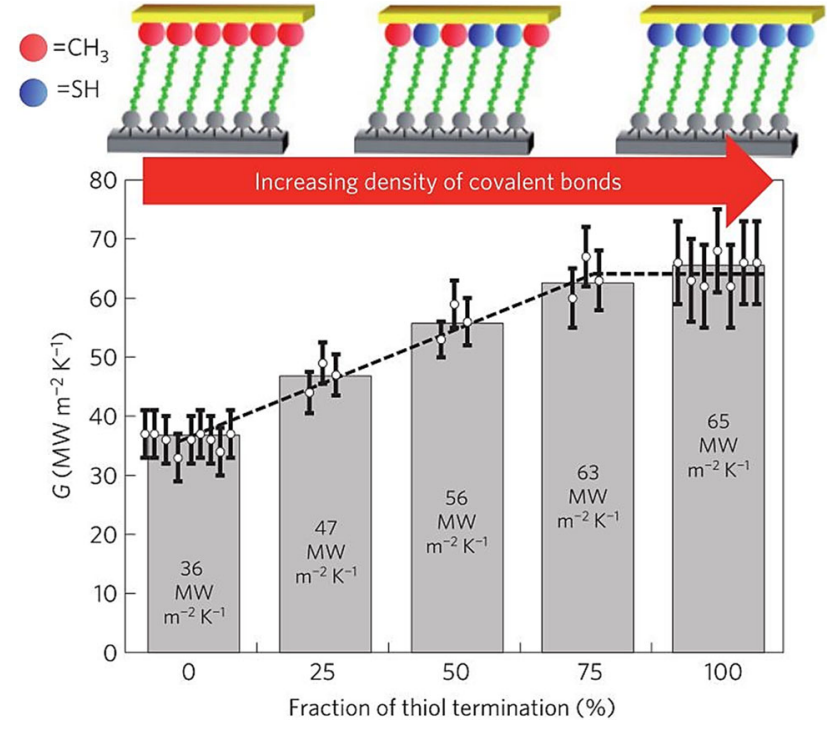

Figure 25 Tuning interface thermal conductance. Plot of interface thermal conductance $(G)$ as a function of the methyl:thiol endgroup ratio for $0 \%, 25 \%, 50 \%, 75 \%$ and $100 \%$ thiol end groups. Duplicated Al for each ratio was measured. Error bars represent uncertainty in TDTR data fitting [98].

$\gamma=\frac{a \sigma_{\mathrm{cm}}^{2}}{12 E_{\mathrm{m}}\left((1 / \bar{\varepsilon})+v_{p}\right)}$

$\gamma$ is interfacial bonding energy, $\sigma_{\mathrm{cm}}$ is ultimate tensile strength, $a$ is volume to surface area ratio of the reinforcement, $E_{\mathrm{m}}$ is Young's modulus of the matrix, $\bar{\varepsilon}$ is equivalent Young's modulus of the composite, and $v_{p}$ is the volume fraction of the reinforcement. From Eq. (14), it is apparent that the interfacial bonding energy is highly associated with these mechanical parameters, which can be obtained through mechanical testing. Wu et al. also prove that the fracture surface, which has the characteristics shown in Fig. 26c, has the highest interfacial bonding energy. This is attributed to no gaps existed between the diamond particles and the matrix. Furthermore, dimples on the diamond surfaces suggest the metal matrix bonds tightly with the diamond so that the metal side deforms plastically before it detaches from the diamond, compared to the composites that have the microstructures shown in Fig. 26a, b, d.

(E) Measurement of TBC Time-domain thermos-reflectance (TDTR) is a optical technique, which can measure the surface temperature changes from the surface optical reflectivity without contacting. It has a laser pulse and a pump probe, with which the thermal boundary conductance between two the materials with very small scales can be experimentally quantified. This technique has become popular and standardized over the past 20 years [104]. With the progress of pulsed laser systems, this thermos-reflectance technique can employ ultrafast laser with very short pulses to characterize the temperature changes in the time domain. In this way, it reduces the errors radiative loss and contact issues that are concerning in other measurement techniques like the $3 \omega$ method $[28,105,106]$. Thorough descriptions of the measurement methods and data analysis can be found in Refs [96, 107-109]. 

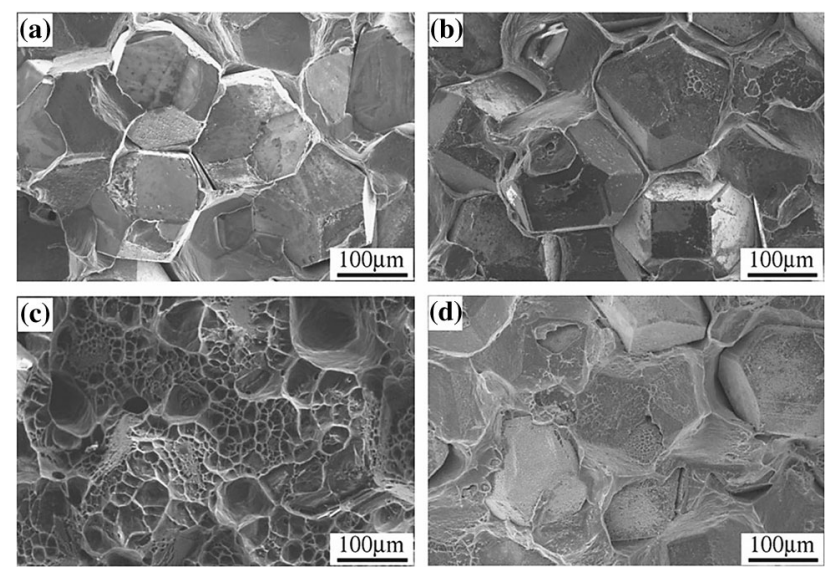

Figure 26 FE-SEM micrographs of tensile fracture surfaces of the $\mathrm{Al} / \mathrm{Ti}$ diamond composites with different plating times of a uncoated, b $30 \mathrm{~min}$, c $90 \mathrm{~min}$, and d $180 \mathrm{~min}$ [103].

TDTR technique is just applied for investigating the interface thermal conductance problem of copper/diamond composites recently [80, 87, 110]. The general principle is that the interface scenario in the copper/diamond composites can be physically simulated through creating a Ti layer by magnetron sputtering onto a diamond substrate, as shown in Fig. 27. Then, the heat treatment is conducted for forming $\mathrm{TiC}$ to simulate the real scenario at the interface of copper/diamond composites. TDTR measurement for this sandwich-structured object can be conducted, and the obtained results can be compared with the theoretical calculation. Therefore, the thermal boundary conductance and interface thermal conductance can be directly measured and compared to the theoretical value (TDTR system is shown in Fig. 28).

As we explained before, the thermal boundary conductance is very important for the thermal conductivity in the copper/diamond composites. The recent published research works indicate that this problem can be dissociated to investigate by measuring TBC between physically simulated layers. Nevertheless, the measured TBC still has some discrepancies compared to the calculated values by AMM and DMM models.

\section{Thermal conductance of the interface layer}

Apart from the thermal boundary conductance, the thermal conductance of the interface layer, $\mathrm{K}_{\mathrm{d}}$ (as indicated in Fig. 19), is another important part to determine the thermal conductivity of the fabricated materials, and it is affected by the following three factors.

(A) Dislocations From the experimental data listed in Tables 1, 2, 3 and 4in "Fabrication and thermal conductivity of copper/diamond composites" section, it shows that the thickness of the interface layer in copper/diamond composites ranges from a few hundred nm up to $2000 \mathrm{~nm}$. In most cases, the mean free path (MFP) of heat carriers (phonons or electrons) at room temperature is quite small, in the order of $<1-3 \mathrm{~nm}$, and this value is far smaller than the thickness of the interface layer. This means that the thermal transfer in the interface layer of the copper/diamond composites is exactly similar to that transferring in the bulk materials, which has been analyzed in "In copper matrix" section.

Researchers investigate the quantified relationship between the crystal dislocation and thermal conductance of the interfacial layer, and the results are shown in Fig. 29 [109]. They find that two orders of magnitude of increase in dislocation densities lead to a factor of two reduction in thermal conductance, demonstrating the detrimental effect of dislocations on the thermal conductance. However, it is hard to directly characterize the dislocation density, making

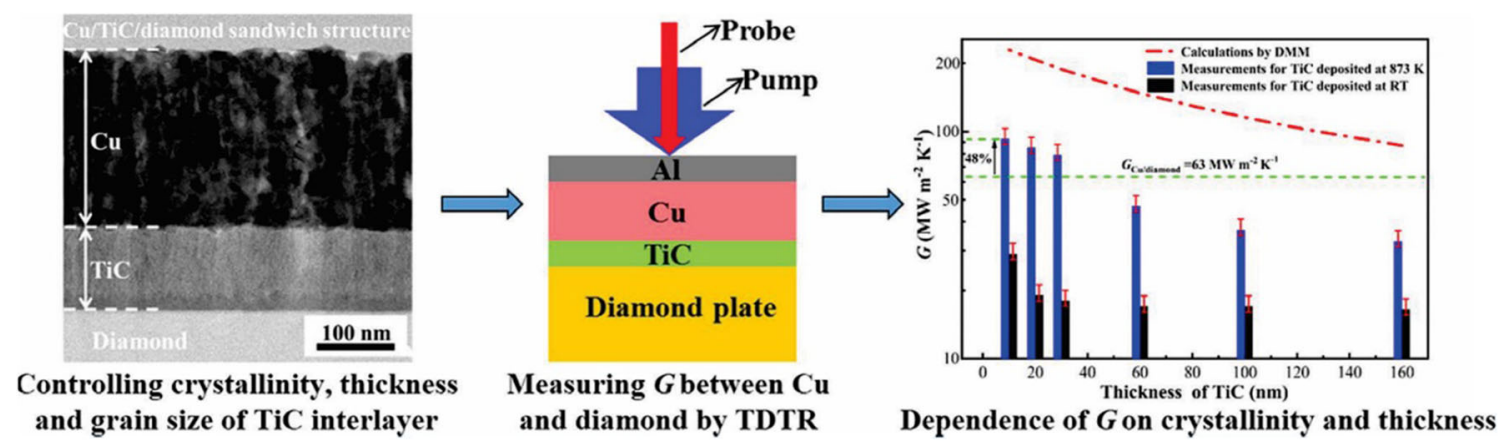

Figure 27 Schematics of the TDTR test of thermal conductance between the TiC layer and diamond substrate [80]. 
Figure 28 Schematic diagram of key components of a TDTR system [87].

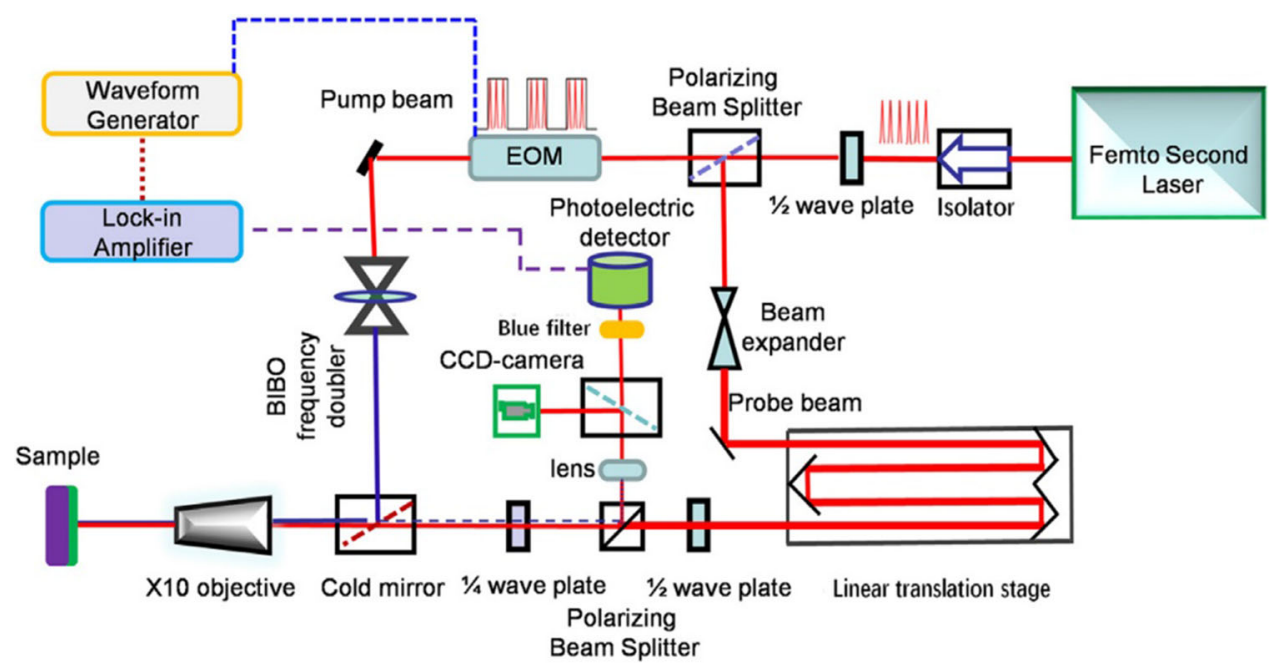

it even harder to establish quantitative forms of functions to describe the dependency of thermal boundary conductance on dislocation density.

(B) The additional interfacial layer If the interface structure is composed of two layers and the thickness for one of the layers is in nano-size, the wave nature of the phonon needs to be considered when the MFP of heat carriers is comparable or larger than the nanosized interface layer. Researchers study the effect of the additional $\mathrm{Cu}$ layer, with a thickness of ranging from a few nanometers to $30 \mathrm{~nm}$, on the thermal boundary conductance between the $\mathrm{Au}$ and the substrate [113], and find that the TBC in the structure of $\mathrm{Au}-\mathrm{Cu}-\mathrm{Al}_{2} \mathrm{O}_{3}$ is increased with increasing the thickness of inserted $\mathrm{Cu}$ layer, as shown in Fig. 30. The improvement in TBC is attributed to the electron-phonon coupling. However, similar research work has been done by Jeong et al., and they claim the additional phonon modes provided by the thin $\mathrm{Cu}$ layer are the dominant mechanism, not electronphonon coupling, for improving TBC [49], and the improved TBC is verified by both experimental measurement and DMM prediction.

(C) Intrinsic property and structure of the interface layer The intrinsic properties of the interface layer can affect the phonon transmission from the two sides of the interface layer. The Debye temperature of the materials that are sitting on the two sides of the interface layer is usually different. According to the assumptions in DMM and AMM, the phonons of the material that is sitting on one side of the interface layer can only couple with the phonons that have

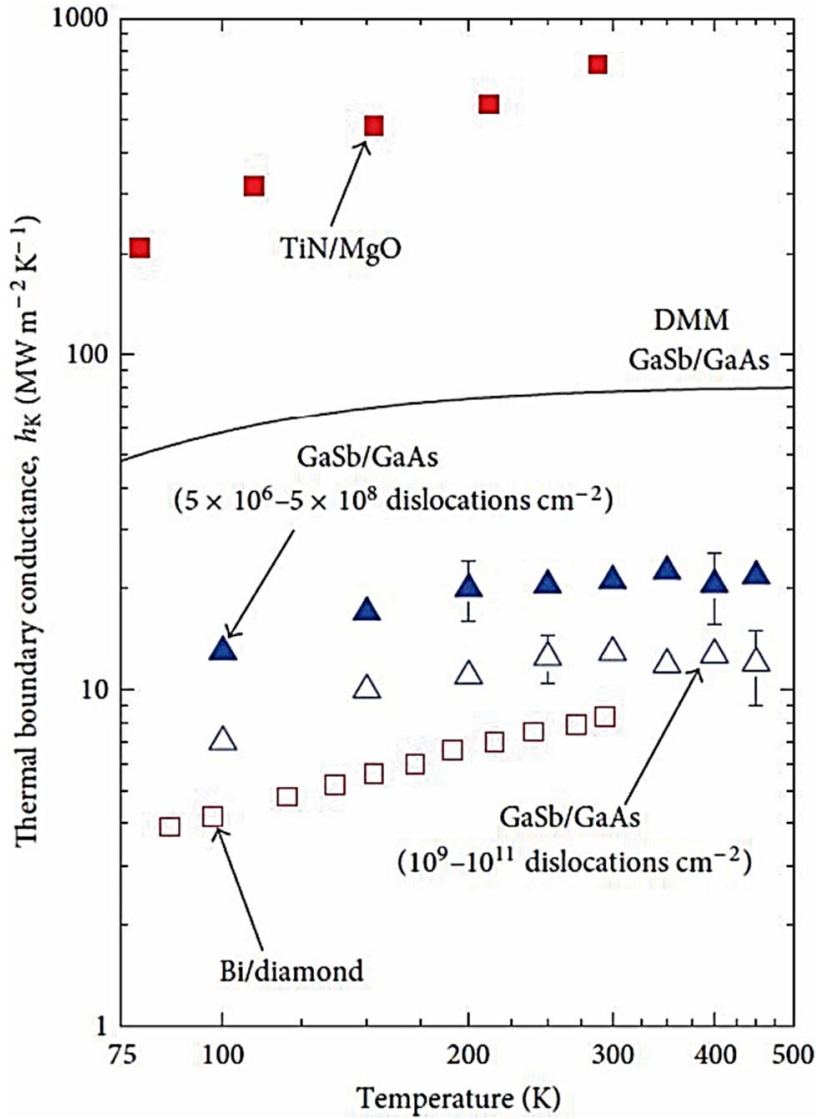

Figure 29 Thermal boundary conductance at the $\mathrm{GaSb} / \mathrm{GaAs}$ interfaces with two different dislocations density from the work [111]. TiN/MgO and $\mathrm{Bi} /$ diamond data for comparison come from work [112] and [29]. The figure is from [109].

identical frequency from the material sit on the other side of the interface layer during transmission process. Large interface vibrational mismatch of the materials on the two sides leads to that very few 


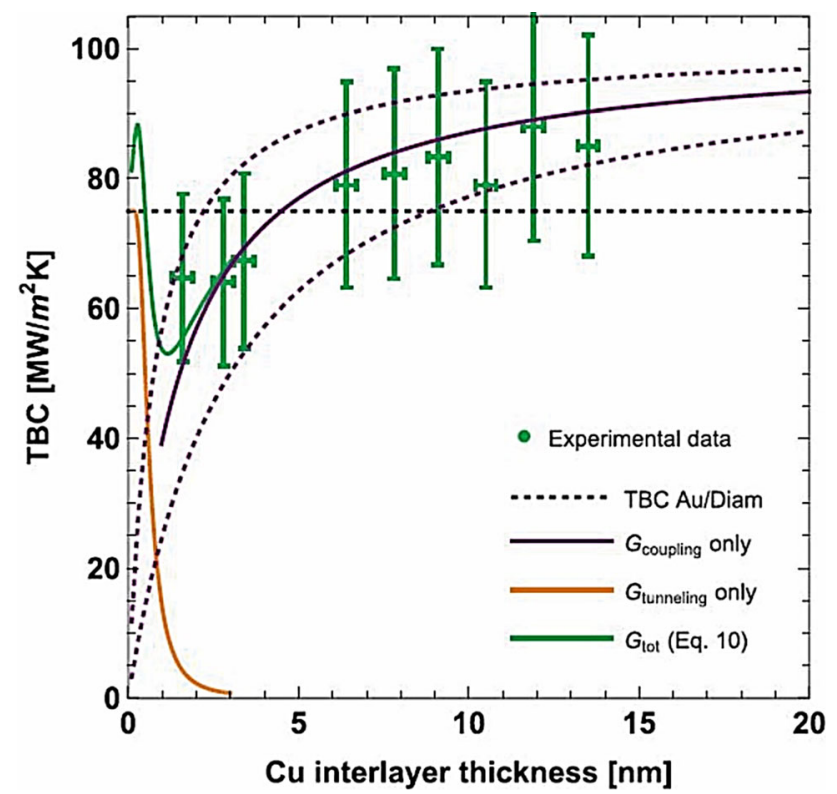

Figure 30 Influence of the addition of a nanometer-sized copper interlayer on the thermal boundary conductance at the $\mathrm{Au} / \mathrm{A}_{2} \mathrm{O}_{3}$ interface. All data and calculations are from Ref [113].

phonon modes can transmit across the interface layer, thus resulting in low interface thermal conductance. If the materials that are sitting on the two sides of the interface layer have a Debye temperature ratio of $5-20$, the obtained $\mathrm{G}$ will be in the range of $8-30 \mathrm{M}$ / $\mathrm{W} \mathrm{m}{ }^{2} \mathrm{~K}$ [29]. The density of state (DOS) of the materials can be used to explain this. In Fig. 31, the DOS of the two materials has little overlapped area so that the thermal vibration from one side of the interface layer cannot stimulate the vibration of the material on the other side. To mediate the discrepancy, a layer with required properties could be inserted between the two materials. For example, the inserted film leads to both materials have a more overlapped DOS area, as indicated by the hatched region in Fig. 32, and this facilitates more phonon transmission. This method has been experimentally applied and demonstrated in copper/diamond composites [80, 114].

The structure of the interface layer can also tune the phonon transmission across the interface. It is possible to design a certain structure to enhance the interface thermal conductance. Insertion of one layer or two layers with mediated Debye temperature aforementioned is a possible method. Is it possible to make a more complex and multiple-layered structure to boost the phonon transmission further? The investigations of the superlattice may shine some light on this problem, even though the topic is toward the reduction in its thermal conductivity, which is opposite to the purpose of this review. Superlattice is a structure with two different materials repeating periodically. Phonon as a kind of quasi-particle has wave-particle duality [117]. When the phonon MFP is smaller than the periodic thickness, it transmits in its particle nature (the descriptions of AMM and DMM are based on its particle nature). When the phonon MFP is comparable or larger than the periodic thickness, its wave nature must be considered. For example, in the incoherent regime in Fig. 33, the particle nature of phonons dominates because the interface density is small (periodic thickness is large or compatible with MFP) [118]. With the interface density increasing, more interface thermal resistance appears, and this leads to the decreased thermal conductivity as shown in Fig. 33. The minimum TC corresponding to a periodic thickness shown in the figure is caused by the phonon band folding $[119,120]$. After this critical TC, the phonons' wave nature dominates in the coherent regime. With higher interface density (much smaller periodic thickness, compared to MFP), phonons can transport ballistically before being reflected at the interface or getting scattered, and this leads to the increased thermal conductivity. The key point that needs to be noticed is that, theoretically, the thermal conductivity of superlattice could surpass the original TC when the interface density is high enough (as shown in Fig. 33). This may enlighten that the additional channels of phonon waves could be utilized by ballistic transport or phonon interference to enhance the interface thermal conductance further if the materials have appropriate periodic thickness and MFP.

\section{Interface thermal conductance calculation}

Interface thermal conductance (ITC) is composed of two parts, TBC and thermal conductance of the interface layer, and the affecting factors on those two parts have been reviewed in "Thermal boundary conductance" and "Thermal conductance of the interface layer" sections, respectively; however, an equation needs to be established for easily evaluating the thermal conductance of the entire interfacial system. Recalling the definition of thermal conductance and expression in Eq. (2), it is comparable to the concept of electric resistance, which is the voltage per electric current, and it is temperature per heat current 


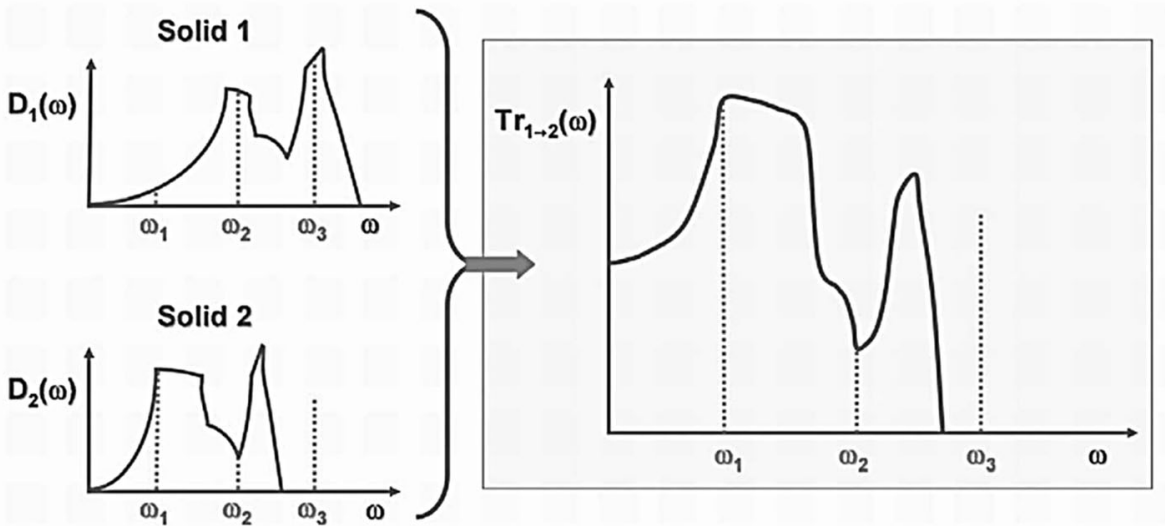

Figure 31 Illustration of the phonon transmission probability as predicted by the Diffuse mismatch model. Given two interface solids, 1 and 2, with vibrational spectra, $D 1(\omega)$ and $D 2(\omega)$, the phonon transmission probability from 1 to $2, \operatorname{Tr}_{1-2}((\omega))$ is dependent on the ratio of the spectra as shown in the figure.

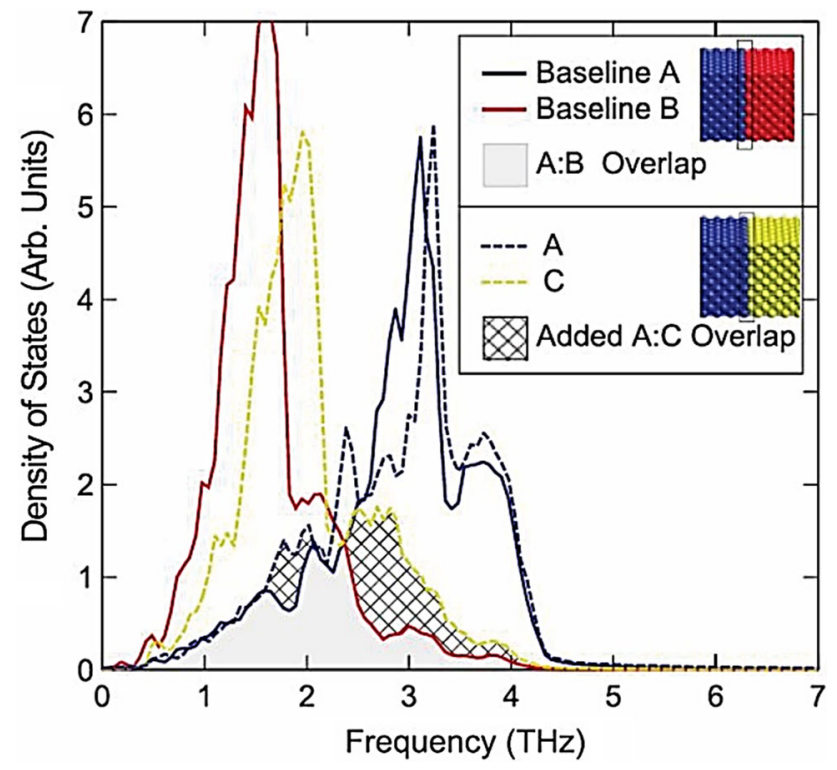

Figure 32 DOS along the $\mathrm{z}$-axis calculated from monolayers containing 72 atoms of material $\mathrm{A}$ and $\mathrm{C}$ in the enhanced interface (dashed lines) in comparison with the baseline interface [116].

for the thermal resistance. The definition of thermal resistance is the inverse of thermal conductance, vice versa.

Hence, we assume that the model in Fig. 19 is the structure of the interface; the expression of interface thermal conductance can be formulated according to the principle in electrical resistance in series law as:

$\frac{1}{h_{\mathrm{c}}}=\frac{1}{G_{1}}+\frac{a}{K_{i}}+\frac{1}{G_{2}}$
Representative locations of maxima and minima in the transmission probability are labeled on $D 1(\omega), D 2(\omega)$, and $\operatorname{Tr}_{1-2}(\omega)$. The transmission probability at $\omega_{3}$ is zero because solid 2 does not vibrate at that frequency [115].



Figure 33 Thermal conductivity of ${ }^{12} \mathrm{C} /{ }^{13} \mathrm{C}$ graphene superlattices as a function of the interface density. The red hollow circles represent the cases with total length of $240 \mathrm{~A}^{\circ}$, and the blue solid squares represent those with total length of $480 \mathrm{~A}^{\circ}$. The black vertical dash line indicates the position of crossover from incoherent to coherent phonon transport [121].

where $h_{\mathrm{c}}$ is the interface thermal conductance; $G_{1}$ and $G_{2}$ represent thermal boundary conductance of the boundaries at both sides of the interface layer. $K_{i}$ represents the thermal conductivity value of the materials composed of an interface; " $a$ " represents the thickness of interface layer. Thus, the value of $G_{1}, G_{2}$ and $K_{i}$ should be considered separately based on the above discussion and review to accurately quantify each value. 
The interface thermal conductance problems should be analyzed from every aspect of the interface system. The complexity in this part lies in handling these factors together in the perspective of phonon as heat carriers mathematically. Especially for thermal boundary conductance, after nearly six decades' research, the underlying mechanisms of the phenomenon are still elusive [27]. The copper/diamond composites provide us the intricate interfacial systems to delve into this interesting problem, and probably these materials can be used to verify the theory from the experimental results.

\section{Model prediction of effective thermal conductivity of copper/diamond composites}

We already reviewed some research results of the synthesized copper/diamond composites and factors that influence the thermal transfer efficiency of the composites in the above sections. Some of the factors are described in the form of functions to quantify their influence on the thermal transfer process. Hence, here we review calculation models for predicting the effective thermal conductivity of heterogeneous materials. Before applying the models to copper/diamond composites, we assume that all factors mentioned above are taken into account; for example, we assume that the interface thermal conductance and thermal conductivity values of a copper matrix and diamond are measured or calculated as discussed in "Factors affecting the thermal conductivity of copper/diamond composites" section.

\section{Maxwell model}

Due to the similar mathematical nature of electric current and heat current transmitting in materials, the principles of Maxwell's findings on electric are applied in heat transfer problems. Maxwell is the first to give expressions for the effective electric conductivity of heterogeneous materials in his famous work on electricity and magnetism [122]. The formula is given by replacing the concept of electric conductivity with thermal conductivity:

$\frac{k_{\mathrm{c}}}{k_{\mathrm{m}}}=1+\frac{3 V_{\mathrm{d}}}{\left(\frac{k_{\mathrm{d}}+2 k_{\mathrm{m}}}{k_{\mathrm{d}}-k_{\mathrm{m}}}\right)-V_{\mathrm{d}}}$ where $k_{\mathrm{c}}, k_{\mathrm{m}}$ and $k_{\mathrm{d}}$ are the thermal conductivity of composite, matrix, and dispersed reinforcement particles, respectively. $V_{\mathrm{d}}$ represents the volume percentage of reinforcement particles. Maxwell deduces the expression based on the assumption that the dispersed particles with spherical shape are diluted embedded in a continuous matrix and non-interacting. This indicates that the Maxwell model is accurate only for low volume percentage of reinforced particles and the situation of reinforced particles contacting each other is absent. Also, interfacial resistance and size of the reinforced particles are not considered in this model. Since the shape of diamond particles is cuboctahedron and is very close to the sphere, it is appropriate to apply this model to copper/diamond composites. When applying this model to copper/diamond composites, as the interface thermal resistance between the copper matrix and the diamond particles cannot be ignored, large discrepancy between experimental value and model prediction is obvious [20, 24,40]. One research work shows the large discrepancy between experimental and calculated values when applying the Maxwell model, as shown in Fig. 34 [20]. The blue dot in the picture, corresponding to the composites with uncoated diamond, shows an opposite tendency in contrast with the modeled results. This is because the model is developed under the assumption that no pore or gaps are existed in the matrix or near the interface area. However, with uncoated diamond, the gaps probably appear around the diamond particle reinforcements due to the poor chemical affinity between the diamond and the copper.

\section{Hasselman-Johnson model}

Hasselman and Johnson considered the interface thermal conductance among the reinforced particles and the size effect of reinforced particles, they deduce the Hasselman-Johnson model ( $\mathrm{H}-\mathrm{J}$ model) based on the work of Maxwell, and the deduction details can be found in Ref [123]. The expression is given:

$k_{\mathrm{c}}=k_{\mathrm{m}} \frac{\left[2\left(\frac{K_{\mathrm{d}}}{K_{\mathrm{m}}}-\frac{K_{\mathrm{d}}}{a h_{\mathrm{c}}}-1\right) V_{\mathrm{d}}+\frac{K_{\mathrm{d}}}{K_{\mathrm{m}}}+\frac{2 K_{\mathrm{d}}}{a h_{\mathrm{c}}}+2\right]}{\left[\left(1-\frac{K_{\mathrm{d}}}{K_{\mathrm{m}}}+\frac{K_{\mathrm{d}}}{a h_{\mathrm{c}}}\right) V_{\mathrm{d}}+\frac{K_{\mathrm{d}}}{K_{\mathrm{m}}}+\frac{2 K_{\mathrm{d}}}{a h_{\mathrm{c}}}+2\right]}$

where " $a$ " is the radius of the dispersed particles; $h_{\mathrm{c}}$ is the interface thermal conductance. It can also be written in this form: 


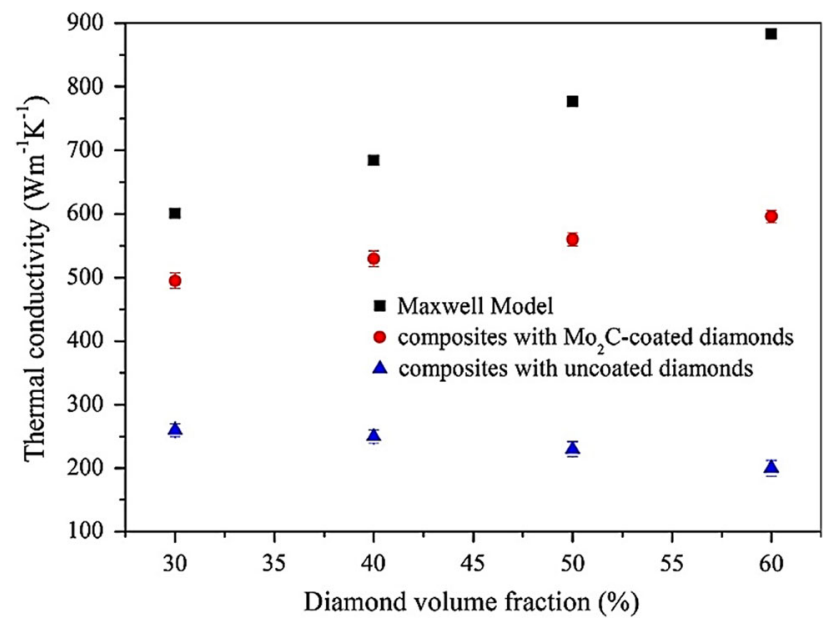

Figure 34 Thermal conductivity of copper-diamond composites with uncoated and $\mathrm{Mo}_{2} \mathrm{C}$-coated diamond particles [20].

$k_{\mathrm{c}}=k_{\mathrm{m}} \frac{\frac{k_{\mathrm{m}}^{\text {eff }}}{K_{\mathrm{m}}}\left(1+2 V_{\mathrm{d}}\right)+\left(2-2 V_{\mathrm{d}}\right)}{\frac{\kappa_{\mathrm{d}}^{\text {eff }}}{\kappa_{\mathrm{m}}}\left(1-V_{\mathrm{d}}\right)+\left(2+V_{\mathrm{d}}\right)}$

the meaning of $k_{\mathrm{d}}^{\mathrm{eff}}$ is given in Eq. (20).

Since the H-J model considers the interface thermal resistance and the reinforced particle sizes, it has better prediction results than the Maxwell model. However, the model still has the same restriction as the Maxwell model, and it is only accurate for the composite with a low volume percentage of reinforcement. Due to the simplicity of the H-J model, it has been applied in many research works for predicting copper/diamond composites' thermal conductivity [21, 32, 48, 124]. The H-J model can basically reflect the tendency of diamond volume percentage versus thermal conductivity of the copper/diamond composites after considering the ITC, as shown in Fig. 35 [41], although the discrepancy between the experimental value and prediction is very obvious.

\section{Differential effective medium (DEM) model}

DEM model is an improved version of the former ones, which can be deduced directly from the H-J model; the threads and details can be found in Refs $[125,126]$. The expressions of DEM are:

$\left(1-V_{\mathrm{d}}\right)\left(\frac{k_{\mathrm{c}}}{k_{\mathrm{m}}}\right)^{\frac{1}{3}}=\frac{k_{\mathrm{d}}^{\text {eff }}-k_{\mathrm{c}}}{k_{\mathrm{d}}^{\text {eff }}-k_{\mathrm{m}}}$ $k_{\mathrm{d}}^{\mathrm{eff}}=\frac{k_{\mathrm{d}}}{1+\frac{k_{\mathrm{d}}}{a h_{\mathrm{c}}}}$

The meanings of symbols in these equations are the same as those in Maxwell and H-J models. Due to its concise form and simplicity, the DEM model is applied in many works related to copper/diamond composite materials $[6,7,19,87,127]$. Yang et al. find that the $\mathrm{Cu}$ /diamond composite with Ti additive can reach $99 \%$ of the predicted value $(555 \mathrm{~W} / \mathrm{m} \mathrm{K})$ by the DEM model [62]. In another work, the DEM model can give an upper bound for the prediction of thermal conductivity of copper/diamond composites, based on the TDTR-measured TBC value $G$, as shown in Fig. 36 [87].

DEM model is more stable for fitting the experimental data when changing the diamond size or volume percentage [125]. Overall, the DEM model is quite accurate for the prediction of the thermal conductivity of the composites. The deviation from the experimental value could be caused by the geometry of the diamond and the interface thermal conductance.

\section{Comparison of the prediction models}

The sequence of the three models introduced above is that: the latter model is evolved and modified from the former one. Each of the three models has its own applications, which can be found in most of the research works we reviewed in "Fabrication and thermal conductivity of copper/diamond

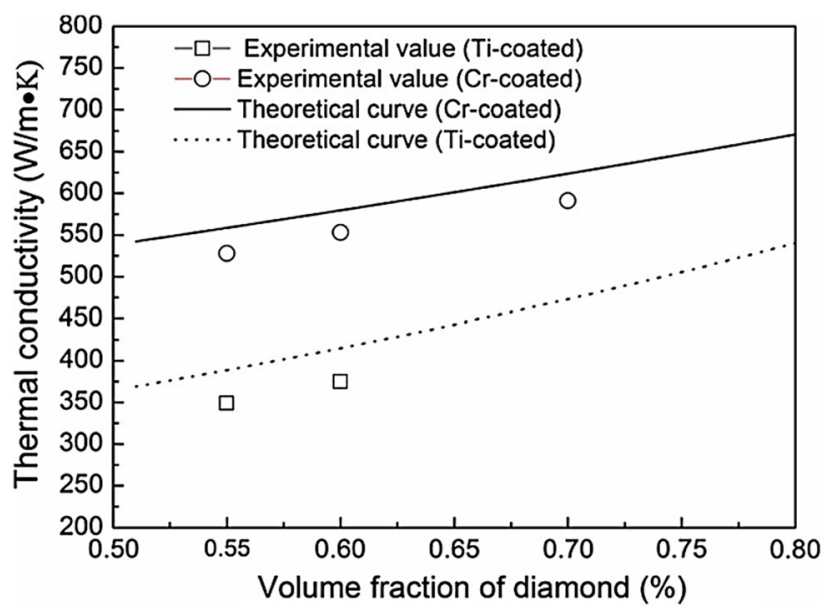

Figure 35 Theoretical curves and experimental values of the thermal conductivity of the composites fabricated using the diamonds coated by $1-\mu \mathrm{m} \mathrm{Cr}_{7} \mathrm{C}_{3}$ or $1-\mu \mathrm{m} \mathrm{TiC}$ layer [41]. 


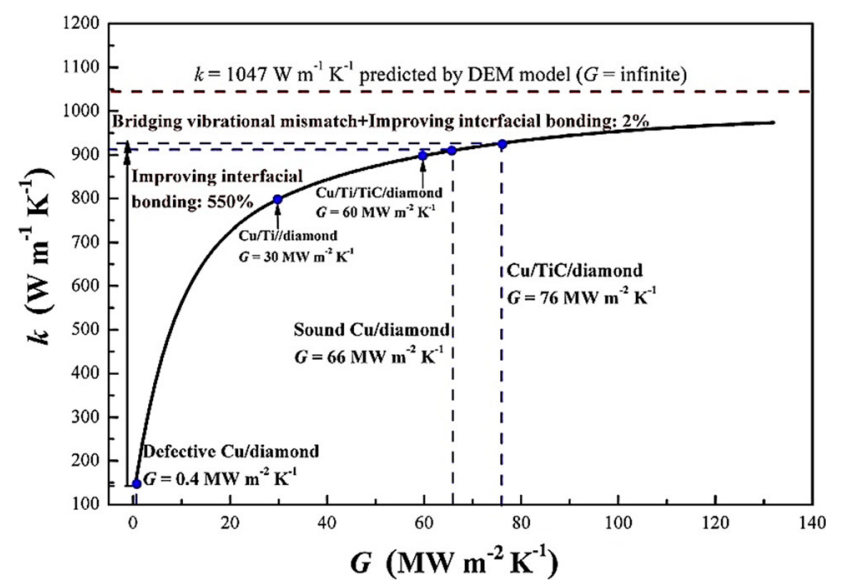

Figure 36 Relation between $\mathrm{G}$ of $\mathrm{Cu} /$ diamond interface and $\mathrm{k}$ of $\mathrm{Cu} /$ diamond composite established by the DEM model [87].

composites" section. The classic Maxwell model is easy to be used for predicting the upper limit of thermal conductivity value of copper/diamond composites with a certain volume fraction of diamonds, because the most important factor, interface thermal conductance, in this model $h_{\mathrm{c}}=\infty$. In the HJ model, ITC and diamond sizes are considered; the accuracy for prediction is improved compared to the Maxwell model. For the DEM model, a new term $k_{\mathrm{d}}^{\text {eff }}$ is introduced, which can be understood that the reinforced particle with the size of " $a$ " is considered as a new reinforced particle (a unity) that has an effective thermal conductivity $k_{\mathrm{d}}^{\text {eff }}$ with ITC " $h "=\infty$. This is also reflected in Eq. (18). Thus, DEM can also be used to estimate the interface thermal conductance by inversely considering this issue. The steps are: (1) calculating the $k_{\mathrm{d}}^{\text {eff }}$ with known $k_{\mathrm{c}}$ by experimental measurement based on Eq. (19); (2) rewriting Eq. (20) to:

$\frac{1}{k_{\mathrm{d}}^{\mathrm{eff}}}=\frac{1}{k_{\mathrm{d}}}+\frac{1}{h_{\mathrm{c}}} \frac{1}{a}$

and then plotting $\left(k_{\mathrm{d}}^{\text {eff }}\right)^{-1}$ against $a^{-1}$ to yield the line with slope $h_{\mathrm{c}}^{-1}$, to obtain the ITC. The estimation of uncertainty by this inversed method can be found in Ref [28].

\section{Conclusions and outlook}

Copper/diamond composites have great potential to lead the next generation of heat sink materials for high-power electronic devices use, with potential thermal conductivity $>500 \mathrm{~W} /(\mathrm{m} \mathrm{K})$ and a thermal expansion coefficient that is tunable to match with that of chip materials, in the range of $4-6 \mathrm{ppm} / \mathrm{K}$. However, their potentially high thermal conductivity is strongly dependent on the quality of the copper/diamond interface, which is disrupted by the poor chemical affinity between the copper and the diamond. The interface layer acts as a "bridge" to improve the efficiency of thermal transferring between the diamond particles and the copper matrix. The interface layer's characteristics determine the interface thermal conductance that is crucial for having high thermal conductivity for the copper/diamond composites, and it is also vital for obtaining high conductive copper/diamond composite to require the composite has a matrix with low defect level and high-quality diamond particle reinforcement. Through the understanding on how heat carries across the interface layer boundary and transfers in the interlayer structure from physical perspectives, we have identified some factors, such as the boundary surface roughness, atomic intermixing, interfacial bonding strength, contrast of the DOS, and the structure of interfacial layers that could significantly influence the interfacial layer's thermal boundary conductance and thermal conductance, thus further affecting the thermal conductivity of copper/diamond composites. To engineer a copper/diamond composite for meeting the thermal conductivity requirement of practical applications, we need to have an in-depth understanding on how the interfacial layer's characteristics influence the heat transfer from the diamond to copper, establish a quantitative relationship between those factors and the resultant thermophysical properties, and expand the relationship including the processing, eventually establishing the processing-interfacial layer characteristics (microstructures)-thermophysical properties relationship for the copper/diamond composites. This understanding is lacking or not unified; currently, more research work needs to be carried in this regard. Furthermore, diamond is very hard and the composite's machinability becomes very poor when diamond particles are integrated into the copper matrix, making it very challenging to machine copper/diamond composites into specific products for practical use. Near-net shape forming technology for producing copper/diamond composites is necessary, and this would be a game changer that enables us to achieve cost-effective production of copper/diamond 
products with specific geometry requirements and bring the copper/diamond products to a wide market for high-power thermal management requirements. The potential near-net shaping technology for producing copper/diamond composites could be but not limited to additive manufacturing such as selective laser melting, direct energy deposition, or binder jetting.

\section{Acknowledgement}

This work was supported by the US Air Force Office of Scientific Research under Award Number FA238617-1-4025.

Open Access This article is licensed under a Creative Commons Attribution 4.0 International License, which permits use, sharing, adaptation, distribution and reproduction in any medium or format, as long as you give appropriate credit to the original author(s) and the source, provide a link to the Creative Commons licence, and indicate if changes were made. The images or other third party material in this article are included in the article's Creative Commons licence, unless indicated otherwise in a credit line to the material. If material is not included in the article's Creative Commons licence and your intended use is not permitted by statutory regulation or exceeds the permitted use, you will need to obtain permission directly from the copyright holder. To view a copy of this licence, visit http://creativecommons.org/licen ses/by/4.0/.

\section{Author contributions}

S. Q. J. participated in writing-original draft, investigation, formal analysis; F. Y. took part in conceptualization, methodology, investigation, writing-review and editing, supervision, and funding acquisition.

\section{References}

[1] Moore AL, Shi L (2014) Emerging challenges and materials for thermal management of electronics. Mater Today 17:163-174. https://doi.org/10.1016/j.mattod.2014.04.003

[2] Monje IE, Louis E, Molina JM (2012) Aluminum/diamond composites: a preparative method to characterize reactivity and selectivity at the interface. Scr Mater 66:789-792. h ttps://doi.org/10.1016/j.scriptamat.2012.02.012

[3] Smoyer JL, Norris PM (2018) Brief historical perspective in thermal management and the shift toward management at the nanoscale. Heat Transf Eng 40:269-282. https://doi.org/ $10.1080 / 01457632.2018 .1426265$

[4] Kidalov S, Shakhov F (2009) Thermal conductivity of diamond composites. Materials 2:2467-2495. https://doi.o $\mathrm{rg} / 10.3390 / \mathrm{ma} 2042467$

[5] Yoshida K, Morigami H (2004) Thermal properties of diamond/copper composite material. Microelectron Reliab 44:303-308. https://doi.org/10.1016/s0026-2714(03)00215 $-4$

[6] Wang L, Li J, Che Z et al (2018) Combining Cr pre-coating and $\mathrm{Cr}$ to improve the thermal conductivity of diamond particles reinforced $\mathrm{Cu}$ matrix composites. J Alloys Compd 749:1098-1105. https://doi.org/10.1016/j.jallcom.2018.03. 241

[7] Bai G, Li N, Wang X, Wang J, Kim MJ, Zhang H (2018) High thermal conductivity of $\mathrm{Cu}-\mathrm{B}$ /diamond composites prepared by gas pressure infiltration. J Alloys Compd 735:1648-1653. https://doi.org/10.1016/j.jallcom.2017.11. 273

[8] Chen H, Jia C-c, Li S-j, Jia X, Yang X (2012) Selective interfacial bonding and thermal conductivity of diamond/ Cu-alloy composites prepared by HPHT technique. Int Min Met Mater 19:364-371. https://doi.org/10.1007/s12613-01 2-0565-7

[9] Rosinski M, Ciupinski L, Grzonka J, Michalski A, Kurzydlowski KJ (2012) Synthesis and characterization of the diamond/copper composites produced by the pulse plasma sintering (PPS) method. Diam Relat Mater 27-28:29-35. https://doi.org/10.1016/j.diamond.2012.05. 008

[10] Zhang H, Liu Y, Zhang F, Zhang D, Zhu H, Fan T (2018) Hot deformation behavior and processing maps of diamond/Cu composites. Metall Mater Trans A Phys Metall Mater Sci 49a:2202-2212. https://doi.org/10.1007/s11661$018-4547-x$

[11] Zhang H, Qi Y, Li J, Wang J, Wang X (2018) Effect of Zr content on mechanical properties of diamond $/ \mathrm{Cu}-\mathrm{Zr}$ composites produced by gas pressure infiltration. J Mater Eng Perform 27:714-720. https://doi.org/10.1007/s11665-0173097-5

[12] Cao H, Tan Z, Fan G et al (2020) Wide and fine alignment control and interface modification for high-performance thermally conductive graphite/copper composite. Compos B Eng. 191:107965. https://doi.org/10.1016/j.compositesb. 2020.107965 
[13] Nikhilesh C, Krishan KC (2006) Metal matrix composites. Springer, New York

[14] Polanco CA, Rastgarkafshgarkolaei R, Zhang J, Le NQ, Norris PM, Ghosh AW (2017) Design rules for interfacial thermal conductance: building better bridges. Phys Rev B Condens Matter. 95:195303. https://doi.org/10.1103/Phys RevB.95.195303

[15] Raza K, Khalid FA (2014) Optimization of sintering parameters for diamond-copper composites in conventional sintering and their thermal conductivity. J Alloys Compd 615:111-118. https://doi.org/10.1016/j.jallcom.2014.06. 139

[16] He J, Zhang H, Zhang Y, Zhao Y, Wang X (2014) Effect of boron addition on interface microstructure and thermal conductivity of $\mathrm{Cu}$ /diamond composites produced by high temperature-high pressure method. Phys Status Solidi (a) 211:587-594. https://doi.org/10.1002/pssa.201330237

[17] Chu K, Jia C, Guo H, Li W (2012) Microstructure and thermal conductivity of $\mathrm{Cu}-\mathrm{B} /$ diamond composites. J Compos Mater 47:2945-2953. https://doi.org/10.1177/ 0021998312460259

[18] Sun Y, He L, Zhang C et al (2017) Enhanced tensile strength and thermal conductivity in copper diamond composites with $\mathrm{B}_{4} \mathrm{C}$ coating. Sci Rep 7:10727. https://doi. org/10.1038/s41598-017-11142-y

[19] Li J, Wang X, Qiao Y, Zhang Y, He Z, Zhang H (2015) High thermal conductivity through interfacial layer optimization in diamond particles dispersed $\mathrm{Zr}$-alloyed $\mathrm{Cu}$ matrix composites. Scr Mater 109:72-75. https://doi.org/ 10.1016/j.scriptamat.2015.07.022

[20] Kang Q, He X, Ren S et al (2013) Effect of molybdenum carbide intermediate layers on thermal properties of copper-diamond composites. J Alloys Compd 576:380-385. h ttps://doi.org/10.1016/j.jallcom.2013.04.121

[21] Bai H, Ma N, Lang J, Zhu C, Ma Y (2013) Thermal conductivity of $\mathrm{Cu} /$ diamond composites prepared by a new pretreatment of diamond powder. Compos B Eng 52:182-186. https://doi.org/10.1016/j.compositesb.2013.04 .017

[22] He J, Wang X, Zhang Y, Zhao Y, Zhang H (2015) Thermal conductivity of $\mathrm{Cu}-\mathrm{Zr}$ /diamond composites produced by high temperature-high pressure method. Compos B Eng 68:22-26. https://doi.org/10.1016/j.compositesb.2014.08. 023

[23] Sang J, Yang W, Zhu J, Fu L, Li D, Zhou L (2018) Regulating interface adhesion and enhancing thermal conductivity of diamond/copper composites by ion beam bombardment and following surface metallization pretreatment. J Alloys Compd 740:1060-1066. https://doi.org/ 10.1016/j.jallcom.2018.01.078
[24] Grzonka J, Kruszewski MJ, Rosiński M, Ciupiński Ł, Michalski A, Kurzydłowski KJ (2015) Interfacial microstructure of copper/diamond composites fabricated via a powder metallurgical route. Mater Charact 99:188-194. https://doi.org/10.1016/j.matchar.2014.11.032

[25] Dong H, Wen B, Melnik R (2014) Relative importance of grain boundaries and size effects in thermal conductivity of nanocrystalline materials. Sci Rep 4:7037. https://doi.org/ 10.1038/srep07037

[26] Li JW, Zhang HL, Zhang Y, Che ZF, Wang XT (2015) Microstructure and thermal conductivity of $\mathrm{Cu}$ /diamond composites with Ti-coated diamond particles produced by gas pressure infiltration. J Alloys Compd 647:941-946. h ttps://doi.org/10.1016/j.jallcom.2015.06.062

[27] Giri A, Hopkins PE (2019) A review of experimental and computational advances in thermal boundary conductance and nanoscale thermal transport across solid interfaces. Adv. Funct. Mater. https://doi.org/10.1002/adfm. 201903857

[28] Monachon C, Weber L, Dames C (2016) Thermal boundary conductance: a materials science perspective. Annu Rev Mater Sci 46:433-463. https://doi.org/10.1146/annurev-ma tsci-070115-031719

[29] Lyeo H-K, Cahill DG (2006) Thermal conductance of interfaces between highly dissimilar materials. Phys Rev B: Condens Matter. 73:144301. https://doi.org/10.1103/Phys RevB.73.144301

[30] Tan Z, Li Z, Fan G et al (2013) Diamond/aluminum composites processed by vacuum hot pressing: microstructure characteristics and thermal properties. Diamond Relat Mater 31:1-5. https://doi.org/10.1016/j.diamond.2012.10. 008

[31] Hu H, Kong J (2013) Improved thermal performance of diamond-copper composites with boron carbide coating. J Mater Eng Perform 23:651-657. https://doi.org/10.1007/ s11665-013-0780-Z

[32] Chu K, Jia C, Guo H, Li W (2013) On the thermal conductivity of $\mathrm{Cu}-\mathrm{Zr} /$ diamond composites. Mater Des 45:36-42. https://doi.org/10.1016/j.matdes.2012.09.006

[33] Zhang C, Wang R, Cai Z, Peng C, Feng Y, Zhang L (2015) Effects of dual-layer coatings on microstructure and thermal conductivity of diamond/ $\mathrm{Cu}$ composites prepared by vacuum hot pressing. Surf Coat Technol 277:299-307. h ttps://doi.org/10.1016/j.surfcoat.2015.07.059

[34] Sinha V, Spowart JE (2013) Influence of interfacial carbide layer characteristics on thermal properties of copper-diamond composites. J Mater Sci 48:1330-1341. https://doi. org/10.1007/s10853-012-6878-0

[35] Yuan M, Tan Z, Fan G et al (2018) Theoretical modelling for interface design and thermal conductivity prediction in 
diamond/Cu composites. Diamond Relat Mater 81:38-44. h ttps://doi.org/10.1016/j.diamond.2017.11.010

[36] Mizuuchi K, Inoue K, Agari Y et al (2016) Effect of boron addition on the thermal properties of diamond-particledispersed Cu-matrix composites fabricated by SPS. J Mater Sci Chem Eng 04:1-16. https://doi.org/10.4236/msce.2016. 49001

[37] Che QL, Zhang JJ, Chen XK et al (2015) Spark plasma sintering of titanium-coated diamond and copper-titanium powder to enhance thermal conductivity of diamond/copper composites. Mater Sci Semicond Process 33:67-75. http s://doi.org/10.1016/j.mssp.2015.01.041

[38] Mańkowski P, Dominiak A, Domański R, Kruszewski MJ, Ciupiński $Ł$ (2014) Thermal conductivity enhancement of copper-diamond composites by sintering with chromium additive. J Therm Anal Calorim 116:881-885. https://oi. org/10.1007/s10973-013-3604-3

[39] Congxu Zhu CW, Lang J, Ma Yi, Ma N (2013) Si-coated diamond particles reinforced copper composites fabricated by spark plasma sintering process. Mater Manuf Process 28:143-147. https://doi.org/10.1080/10426914.2012. 746789

[40] Bai H, Ma N, Lang J, Zhu C (2013) Effect of a new pretreatment on the microstructure and thermal conductivity of $\mathrm{Cu} /$ diamond composites. J Alloys Compd 580:382-385. h ttps://doi.org/10.1016/j.jallcom.2013.06.027

[41] Ren S, Shen X, Guo C et al (2011) Effect of coating on the microstructure and thermal conductivities of diamond- $\mathrm{Cu}$ composites prepared by powder metallurgy. Compos Sci Technol 71:1550-1555. https://doi.org/10.1016/j.compscit ech.2011.06.012

[42] Schubert T, Trindade B, Weißgärber T, Kieback B (2008) Interfacial design of $\mathrm{Cu}$-based composites prepared by powder metallurgy for heat sink applications. Mater Sci Eng A 475:39-44. https://doi.org/10.1016/j.msea.2006.12. 146

[43] Dong YH, Zhang RQ, He XB, Ye ZG, Qu XH (2012) Fabrication and infiltration kinetics analysis of Ti-coated diamond/copper composites with near-net-shape by pressureless infiltration. Mater Sci Eng B-Adv 177:1524-1530. https://doi.org/10.1016/j.mseb.2012.08.009

[44] Bai G, Zhang Y, Dai J, Wang X, Zhang H (2020) Mechanical properties of $\mathrm{Cu}-\mathrm{B} /$ diamond composites prepared by gas pressure infiltration. J Mater Eng Perform 29:3107-3119. https://doi.org/10.1007/s11665-020-047901

[45] Abyzov AM, Kidalov SV, Shakhov FM (2012) High thermal conductivity composite of diamond particles with tungsten coating in a copper matrix for heat sink application. Appl Therm Eng 48:72-80. https://doi.org/10. 1016/j.applthermaleng.2012.04.063

[46] Weber L, Tavangar R (2007) On the influence of active element content on the thermal conductivity and thermal expansion of $\mathrm{Cu}-\mathrm{x}(\mathrm{x}=\mathrm{Cr}, \mathrm{B})$ diamond composites. Scr Mater 57:988-991. https://doi.org/10.1016/j.scriptamat.20 07.08.007

[47] Kang QP, He XB, Ren SB et al (2013) Preparation of copper-diamond composites with chromium carbide coatings on diamond particles for heat sink applications. Appl Therm Eng 60:423-429. https://doi.org/10.1016/j.applther maleng.2013.05.038

[48] Ma S, Zhao N, Shi C et al (2017) Mo 2 c coating on diamond: different effects on thermal conductivity of diamond/al and diamond/ $\mathrm{Cu}$ composites. Appl Surf Sci 402:372-383. https://doi.org/10.1016/j.apsusc.2017.01.078

[49] Jeong M, Freedman JP, Liang HJ et al (2016) Enhancement of thermal conductance at metal-dielectric interfaces using subnanometer metal adhesion layers. Phys Rev Appl. 5:014009. https://doi.org/10.1103/PhysRevApplied.5.014009

[50] Bai G, Wang L, Zhang Y et al (2019) Tailoring interface structure and enhancing thermal conductivity of $\mathrm{Cu} /$ diamond composites by alloying boron to the cu matrix. Mater Charact. 152:265-275. https://doi.org/10.1016/j.matchar.2 019.04.015

[51] Jia J, Bai S, Xiong D, Wang J, Chang J (2019) Effect of tungsten based coating characteristics on microstructure and thermal conductivity of diamond/Cu composites prepared by pressureless infiltration. Ceram Int 45:10810-10818. https://doi.org/10.1016/j.ceramint.2019.0 2.156

[52] Wang L, Li J, Bai G et al (2019) Interfacial structure evolution and thermal conductivity of $\mathrm{Cu}-\mathrm{Zr} /$ diamond composites prepared by gas pressure infiltration. J Alloys Compd 781:800-809. https://doi.org/10.1016/j.jallcom.20 18.12 .053

[53] Chen H, Jia C, Li S (2012) Interfacial characterization and thermal conductivity of diamond/Cu composites prepared by two HPHT techniques. J Mater Sci 47:3367-3375. h ttps://doi.org/10.1007/s10853-011-6180-6

[54] Ekimov EA, Suetin NV, Popovich AF, Ralchenko VG (2008) Thermal conductivity of diamond composites sintered under high pressures. Diamond Relat Mater 17:838-843. https://doi.org/10.1016/j.diamond.2007.12. 051

[55] Cho HJ, Yan D, Tam J, Erb U (2019) Effects of diamond particle size on the formation of copper matrix and the thermal transport properties in electrodeposited copper-diamond composite materials. J Alloys Compd 
791:1128-1137. https://doi.org/10.1016/j.jallcom.2019.03. 347

[56] Arai S, Ueda M (2020) Fabrication of high thermal conductivity copper/diamond composites by electrodeposition under potentiostatic conditions. J Appl Electrochem 50:631-638. https://doi.org/10.1007/s10800-020-01414-3

[57] Arai S, Ueda M (2019) Fabrication of high thermal conductivity $\mathrm{Cu} /$ diamond composites at ambient temperature and pressure. AIP Adv. 9:085309. https://doi.org/10.1063/ 1.5111416

[58] Hagio T, Park J-H, Naruse Y et al (2020) Electrodeposition of nano-diamond/copper composite platings: improved interfacial adhesion between diamond and copper via formation of silicon carbide on diamond surface. Surf. Coat. Technol. 403:126322. https://doi.org/10.1016/j.surfcoat.20 20.126322

[59] Wu Y, Tang Z, Wang Y, Cheng P, Wang H, Ding G (2019) High thermal conductive $\mathrm{Cu}$-diamond composites synthesized by electrodeposition and the critical effects of additives on void-free composites. Ceram Int 45:19658-19668. https://doi.org/10.1016/j.ceramint.2019.06.215

[60] Cho HJ, Kim Y-J, Erb U (2018) Thermal conductivity of copper-diamond composite materials produced by electrodeposition and the effect of $\mathrm{TiC}$ coatings on diamond particles. Compos B Eng 155:197-203. https://doi.org/10. 1016/j.compositesb.2018.08.014

[61] Lei L, Su Y, Bolzoni L, Yang F (2020) Evaluation on the interface characteristics, thermal conductivity, and annealing effect of a hot-forged $\mathrm{Cu}-\mathrm{Ti} /$ diamond composite. J Mater Sci Technol 49:7-14. https://doi.org/10.1016/j.jmst. 2020.02.023

[62] Lei L, Bolzoni L, Yang F (2020) High thermal conductivity and strong interface bonding of a hot-forged $\mathrm{Cu}$ /Ti-coateddiamond composite. Carbon. 168:553-563. https://doi.org/ 10.1016/j.carbon.2020.07.001

[63] Yang F, Sun W, Singh A, Bolzoni L (2018) Effect of minor titanium addition on copper/diamond composites prepared by hot forging. JOM 70:2243-2248. https://doi.org/10.100 7/s11837-018-2815-2

[64] Jia S, Su Y, Bolzoni L, Yang F (2019) Interfacial bonding of chromium-doped copper/diamond composites fabricated by powder metallurgy method. Int J Mod Phys B. https://d oi.org/10.1142/s0217979220400500

[65] Brown RA (1981) The effect of dislocations on thermal conductivity. Le J Phys Colloq 42:271-273. https://doi.org/ 10.1051/jphyscol:1981679

[66] Kotchetkov D, Zou J, Balandin AA, Florescu DI, Pollak FH (2001) Effect of dislocations on thermal conductivity of gan layers. Appl Phys Lett 79:4316-4318. https://doi.org/10. 1063/1.1427153
[67] Abyzov AM, Kruszewski MJ, Ciupiński Ł, Mazurkiewicz M, Michalski A, Kurzydłowski KJ (2015) Diamondtungsten based coating-copper composites with high thermal conductivity produced by pulse plasma sintering. Mater Des 76:97-109. https://doi.org/10.1016/j.matdes.20 15.03.056

[68] Yamamoto Y, Imai T, Tanabe K, Tsuno T, Kumazawa Y, Fujimori N (1997) The measurement of thermal properties of diamond. Diamond Relat Mater 6:1057-1061. https://d oi.org/10.1016/S0925-9635(96)00772-8

[69] Kapitza PL (1941) Heat transfer and superfluidity of helium II. Phys Rev 60:354-355. https://doi.org/10.1103/PhysRev. 60.354

[70] Swartz ET, Pohl RO (1989) Thermal boundary resistance. Rev Mod Phys 61:605-668. https://doi.org/10.1103/RevM odPhys.61.605

[71] Chen L, Chen S, Hou Y (2019) Understanding the thermal conductivity of diamond/copper composites by first-principles calculations. Carbon 148:249-257. https://doi.org/1 0.1016/j.carbon.2019.03.051

[72] Giri A, Hopkins PE (2017) Role of interfacial mode coupling of optical phonons on thermal boundary conductance. Sci Rep 7:11011. https://doi.org/10.1038/s41598-017-104 $82-\mathrm{z}$

[73] Giri A, Foley BM, Hopkins PE (2014) Influence of hot electron scattering and electron-phonon interactions on thermal boundary conductance at metal/nonmetal interfaces. J Heat Transf 136:092401. https://doi.org/10.1115/1. 4027785

[74] Jiang C (2008) First-principles study of structural, elastic, and electronic properties of chromium carbides. Appl Phys Lett 92:041909. https://doi.org/10.1063/1.2838345

[75] Posada-Amarillas AD, Galván H, Castillán FF et al (2002) Electronic properties and chemical bonding of orthorhombic chromium carbide. Phys Stat Sol B 229:1353-1358. h ttps://doi.org/10.1002/1521-3951(200202)229:3<1353::AI D-PSSB1353>3.0.CO;2-O

[76] Zhang X-Y, Xu M, Cao S-Z, Chen W-B, Yang W-Y, Yang Q-Y (2020) Enhanced thermal conductivity of diamond/copper composite fabricated through doping with rare-earth oxide $\mathrm{ScO}_{3}$. Diamond Relat Mater. 104:107755. https://doi.org/10.1016/j.diamond.2020.107755

[77] Hohensee GT, Wilson RB, Cahill DG (2015) Thermal conductance of metal-diamond interfaces at high pressure. Nat Commun 6:6578. https://doi.org/10.1038/ncomms7578

[78] Monachon C, Weber L (2014) Thermal boundary conductance between refractory metal carbides and diamond. Acta Mater 73:337-346. https://doi.org/10.1016/j.actamat.2014. 04.024 
[79] Swartz ET, Pohl RO (1987) Thermal resistance at interfaces. Appl Phys Lett 51:2200-2202. https://doi.org/10.10 $63 / 1.98939$

[80] Chang G, Sun F, Wang L et al (2019) Regulated interfacial thermal conductance between $\mathrm{Cu}$ and diamond by a TiC interlayer for thermal management applications. ACS Appl Mater Interfaces 11:26507-26517. https://doi.org/10.1021/ acsami.9b08106

[81] Sadasivam S, Waghmare UV, Fisher TS (2015) Electronphonon coupling and thermal conductance at a metalsemiconductor interface: first-principles analysis. J Appl Phys. 117:134502. https://doi.org/10.1063/1.4916729

[82] Landry ES, McGaughey AJH (2009) Thermal boundary resistance predictions from molecular dynamics simulations and theoretical calculations. Phys Rev B: Condens Matter. 80:165304. https://doi.org/10.1103/PhysRevB.80.165304

[83] Chu YC, et al (2019) Thermal boundary resistance predictions with non-equilibrium green's function and molecular dynamics simulations. arXiv:1908.11578v1

[84] Hopkins PE, Norris PM, Tsegaye MS, Ghosh AW (2009) Extracting phonon thermal conductance across atomic junctions: nonequilibrium green's function approach compared to semiclassical methods. J Appl Phys. 106:063503. https://doi.org/10.1063/1.3212974

[85] Merabia S, Termentzidis K (2014) Thermal boundary conductance across rough interfaces probed by molecular dynamics. Phys Rev B: Condens Matter. 89:054309. http s://doi.org/10.1103/PhysRevB.89.054309

[86] Ciupiński Ł, Kruszewski MJ, Grzonka J et al (2017) Design of interfacial $\mathrm{Cr}_{3} \mathrm{C}_{2}$ carbide layer via optimization of sintering parameters used to fabricate copper/diamond composites for thermal management applications. Mater Des 120:170-185. https://doi.org/10.1016/j.matdes.2017.02.005

[87] Chang G, Sun F, Duan J et al (2018) Effect of Ti interlayer on interfacial thermal conductance between $\mathrm{Cu}$ and diamond. Acta Mater 160:235-246. https://doi.org/10.1016/j. actamat.2018.09.004

[88] Drchal V, Kudrnovský J, Bruno P, Dederichs PH, Turek I, Weinberger P (2002) Electron transport in magnetic multilayers: effect of disorder. Phys Rev B: Condens Matter. 65:214414. https://doi.org/10.1103/PhysRevB.65.214414

[89] Gundrum BC, Cahill DG, Averback RS (2005) Thermal conductance of metal-metal interfaces. Phys Rev B: Condens Matter. 72:245426. https://doi.org/10.1103/PhysRev B. 72.245426

[90] Hopkins PE, Beechem TE, Duda JC, Smoyer JL, Norris PM (2010) Effects of subconduction band excitations on thermal conductance at metal-metal interfaces. Appl Phys Lett. 96:011907. https://doi.org/10.1063/1.3276908
[91] Duda JC, Hopkins PE (2012) Systematically controlling kapitza conductance via chemical etching. Appl Phys Lett. 100:111602. https://doi.org/10.1063/1.3695058

[92] Hopkins PE, Duda JC, Petz CW, Floro JA (2011) Controlling thermal conductance through quantum dot roughening at interfaces. Phys Rev B: Condens Matter. 84:035438. https://doi.org/10.1103/PhysRevB.84.035438

[93] Hopkins PE, Phinney LM, Serrano JR, Beechem TE (2010) Effects of surface roughness and oxide layer on the thermal boundary conductance at aluminum/silicon interfaces. Phys Rev B: Condens Matter. 82:085307. https://doi.org/10.110 3/PhysRevB.82.085307

[94] Wu X, Li L, Zhang W, Song M, Yang W, Peng K (2019) Effect of surface roughening on the interfacial thermal conductance of diamond/copper composites. Diamond Relat Mater 98:107467. https://doi.org/10.1016/j.diamond. 2019.107467

[95] Lee E, Menumerov E, Hughes RA, Neretina S, Luo T (2018) Low-cost nanostructures from nanoparticle-assisted large-scale lithography significantly enhance thermal energy transport across solid interfaces. ACS Appl Mater Interfaces 10:34690-34698. https://doi.org/10.1021/acsam i. $8 \mathrm{~b} 08180$

[96] Hopkins PE, Norris PM, Stevens RJ, Beechem TE, Graham $\mathrm{S}$ (2008) Influence of interfacial mixing on thermal boundary conductance across a chromium/silicon interface. J Heat Transf 130:062402. https://doi.org/10.1115/1. 2897344

[97] Yang L, Shen P, Lin Q, Qiu F, Jiang Q (2011) Effect of Cr on the wetting in $\mathrm{Cu} /$ graphite system. Appl Surf Sci 257:6276-6281. https://doi.org/10.1016/j.apsusc.2011.02. 060

[98] Losego MD, Grady ME, Sottos NR, Cahill DG, Braun PV (2012) Effects of chemical bonding on heat transport across interfaces. Nat Mater 11:502-506. https://doi.org/10.1038/ nmat3303

[99] Hopkins PE, Baraket M, Barnat EV et al (2012) Manipulating thermal conductance at metal-graphene contacts via chemical functionalization. Nano Lett 12:590-595. https://d oi.org/10.1021/n1203060j

[100] Wang F, Chu K, Li Y-B, Wang X-H (2018) Enhanced interfacial bonding and mechanical properties of graphene/ $\mathrm{Cu}$ composites: a matrix-alloying method. Phys Status Solidi (a). 215:1800104. https://doi.org/10.1002/pssa. 201800104

[101] Chu K, Wang F, Li Y-B, Wang X-H, Huang D-J, Zhang H (2018) Interface structure and strengthening behavior of graphene/Cu-Cr composites. Carbon 133:127-139. http s://doi.org/10.1016/j.carbon.2018.03.018 
[102] Zhang H, Wu J, Zhang Y, Li J, Wang X, Sun Y (2015) Mechanical properties of diamond/Al composites with Ticoated diamond particles produced by gas-assisted pressure infiltration. Mater Sci Eng A 626:362-368. https://doi.org/ 10.1016/j.msea.2014.11.077

[103] Wu JH, Zhang HL, Zhang Y, Li JW, Wang XT (2013) The role of Ti coating in enhancing tensile strength of $\mathrm{Al} / \mathrm{dia}-$ mond composites. Mater Sci Eng A 565:33-37. https://doi. org/10.1016/j.msea.2012.11.124

[104] Regner KT, Sellan DP, Su Z, Amon CH, McGaughey AJ, Malen JA (2013) Broadband phonon mean free path contributions to thermal conductivity measured using frequency domain thermoreflectance. Nat Commun 4:1640. h ttps://doi.org/10.1038/ncomms2630

[105] Cahill DG (1990) Thermal conductivity measurement from 30 to $750 \mathrm{k}$ : the $3 \omega$ method. Rev Sci Instrum 61:802-808. h ttps://doi.org/10.1063/1.1141498

[106] Hopkins PE, Phinney LM (2009) Thermal conductivity measurements on polycrystalline silicon microbridges using the $3 \omega$ technique. J Heat Transf 131:2-9. https://doi.org/10. $1115 / 1.3072907$

[107] Jiang P, Qian X, Yang R (2018) Tutorial: time-domain thermoreflectance (TDTR) for thermal property characterization of bulk and thin film materials. J Appl Phys 124:161103. https://doi.org/10.1063/1.5046944

[108] Zhao D, Qian X, Gu X et al (2016) Measurement techniques for thermal conductivity and interfacial thermal conductance of bulk and thin film materials. J Electron Packag 138:040802.1-040802.19. https://doi.org/10.1115/ 1.4034605

[109] Hopkins PE (2013) Thermal transport across solid interfaces with nanoscale imperfections: effects of roughness, disorder, dislocations, and bonding on thermal boundary conductance. ISRN Mech Eng 2013:1-19. https://doi.org/ $10.1155 / 2013 / 682586$

[110] Liu X, Sun F, Wang L et al (2020) The role of Cr interlayer in determining interfacial thermal conductance between $\mathrm{Cu}$ and diamond. Appl Surf Sci. 515:146046. https://doi.org/ 10.1016/j.apsusc.2020.146046

[111] Hopkins PE, Duda JC, Clark SP et al (2011) Effect of dislocation density on thermal boundary conductance across GaSb/GaAs interfaces. Appl Phys Lett. 98:161913. https://doi.org/10.1063/1.3581041

[112] Costescu RM, Wall MA, Cahill DG (2003) Thermal conductance of epitaxial interfaces. Phys Rev B: Condens Matter. 67:054302. https://doi.org/10.1103/PhysRevB.67. 054302

[113] Blank M, Weber L (2018) Influence of the thickness of a nanometric copper interlayer on $\mathrm{Au} /$ dielectric thermal boundary conductance. J Appl Phys. 124:105304. https://d oi.org/10.1063/1.5030049

[114] Azina C, Cornu I, Silvain J-F, Lu Y, Battaglia J-L (2019) Effect of titanium and zirconium carbide interphases on the thermal conductivity and interfacial heat transfers in copper/diamond composite materials. AIP Adv 9:055315. htt ps://doi.org/10.1063/1.5052307

[115] Carey VP, Chen G, Grigoropoulos C, Kaviany M, Majumdar A (2008) A review of heat transfer physics. Nanoscale Microscale Thermophys Eng 12:1-60. https://d oi.org/10.1080/15567260801917520

[116] English TS, Duda JC, Smoyer JL, Jordan DA, Norris PM, Zhigilei LV (2012) Enhancing and tuning phonon transport at vibrationally mismatched solid-solid interfaces. Phys Rev B: Condens Matter. 85:035438. https://doi.org/10.110 3/PhysRevB.85.035438

[117] Ravichandran J, Yadav AK, Cheaito R et al (2013) Crossover from incoherent to coherent phonon scattering in epitaxial oxide superlattices. Nat Mater 13:168-172. http s://doi.org/10.1038/nmat3826

[118] Cheaito R, Polanco CA, Addamane S et al (2018) Interplay between total thickness and period thickness in the phonon thermal conductivity of superlattices from the nanoscale to the microscale: coherent versus incoherent phonon transport. Phys Rev B: Condens Matter. 97:085306. https://doi. org/10.1103/PhysRevB.97.085306

[119] Maldovan M (2015) Phonon wave interference and thermal bandgap materials. Nat Mater 14:667-674. https://doi.org/ 10.1038/nmat4308

[120] Tamura S-i, Tanaka Y (1999) Phonon group velocity and thermal conduction in superlattices. Phys Rev B: Condens Matter 60:2627. https://doi.org/10.1103/PhysRevB.60.2627

[121] Mu X, Zhang T, Go DB, Luo T (2015) Coherent and incoherent phonon thermal transport in isotopically modified graphene superlattices. Carbon 83:208-216. https://doi. org/10.1016/j.carbon.2014.11.028

[122] Maxwell JC (1954) A treatise on electricity and magnetism. Nature 7:478-480. https://doi.org/10.1038/007478a0

[123] Hasselman DH, Johnson LF (1987) Effective thermal conductivity of composites with interfacial thermal barrier. J Compos Mater 21:508-515. https://doi.org/10.1177/ 002199838702100602

[124] Pan Y, He X, Ren S, Wu M, Qu X (2018) High thermal conductivity of diamond/copper composites produced with $\mathrm{Cu}-\mathrm{ZrC}$ double-layer coated diamond particles. J Mater Sci 53:8978-8988. https://doi.org/10.1007/s10853-018-2184-9

[125] Tavangar R, Molina JM, Weber L (2007) Assessing predictive schemes for thermal conductivity against diamondreinforced silver matrix composites at intermediate phase 
contrast. Scr Mater 56:357-360. https://doi.org/10.1016/j.sc riptamat.2006.11.008

[126] Every AG, Tzou Y, Hasselman DPH, Raj R (1992) The effect of particle size on the thermal conductivity of ZnS/diamond composites. Acta Metall Mater 40:123-129. https://doi.org/10.1016/0956-7151(92)90205-S

[127] Zhang Y, Zhang HL, Wu JH, Wang XT (2011) Enhanced thermal conductivity in copper matrix composites reinforced with titanium-coated diamond particles. Scr Mater 65:1097-1100. https://doi.org/10.1016/j.scriptamat. 2011.09 .028

Publisher's Note Springer Nature remains neutral with regard to jurisdictional claims in published maps and institutional affiliations. 